\title{
Arithmetic processing in children with dyscalculia: An event- related potential study
}

\author{
Sonia Y Cárdenas ${ }^{1}$, Juan Silva-Pereyra ${ }^{2}$, Belén Prieto-Corona ${ }^{2}$, Susana A Castro-Chavira ${ }^{1}$, Thalía Fernández ${ }^{\text {Corresp. } 1}$ \\ ${ }^{1}$ Departamento de Neurobiología Conductual y Cognitiva, Instituto de Neurobiología, Universidad Nacional Autónoma de México, Querétaro, México \\ 2 Facultad de Estudios Superiores Iztacala, Universidad Nacional Autónoma de México, Tlalnepantla, Estado de México, México \\ Corresponding Author: Thalía Fernández \\ Email address: thaliafh@yahoo.com.mx
}

Introduction. Dyscalculia is a specific learning disorder affecting the ability to learn certain math processes, such as arithmetic data recovery. The group of children with dyscalculia is very heterogeneous, in part due to variability in their working memory (WM) deficits. To assess the brain response to arithmetic data recovery, we applied an arithmetic verification task during an event-related potential (ERP) recording. Two effects have been reported: the N400 effect (higher negative amplitude for incongruent than for congruent condition), associated with arithmetic incongruency and caused by the arithmetic priming effect, and the LPC effect (higher positive amplitude for the incongruent compared to the congruent condition), associated with a reevaluation process and modulated by the plausibility of the presented condition. This study aimed to a) compare arithmetic processing between children with dyscalculia and children with good academic performance using ERPs during an addition verification task and b) explore, among children with dyscalculia, the relationship between WM and ERP effects.

Materials \& Methods. EEGs of 22 children with dyscalculia (DYS group) and 22 children with good academic performance (GAP group) were recorded during the performance of an addition verification task. ERPs synchronized with the probe stimulus were computed separately for the congruent and incongruent probes, and included only epochs with correct answers. Mixed 2-way ANOVAs for response times and correct answers were conducted. Comparisons between groups and correlation analyses using ERP amplitude data were carried out through multivariate nonparametric permutation tests.

Results. The GAP group obtained more correct answers than the DYS group. An arithmetic N400 effect was observed in the GAP group but not in the DYS group. Both groups displayed an LPC effect. The larger the LPC amplitude was, the higher the working memory index. Two subgroups were found within the DYS group: one with an average WM index and the other with a lower than average WM index. These subgroups displayed different ERPs patterns.

Discussion. The results indicated that the group of children with dyscalculia was very heterogeneous and therefore failed to show a robust LPC effect. Some of these children had WM deficits. When WM deficits were considered together with dyscalculia, an atypical ERP pattern that reflected their processing difficulties emerged. Their lack of the arithmetic N400 effect suggested that the processing in this step was not useful enough to produce an answer; thus, it was necessary to reevaluate the arithmeticcalculation process (LPC) in order to deliver a correct answer.

Conclusion. Given that dyscalculia is a very heterogeneous deficit, studies examining dyscalculia should consider exploring deficits in WM because the whole group of children with dyscalculia seems to contain at least two subpopulations that differ in their calculation process. 


\section{Arithmetic Processing in Children with Dyscalculia: An}

\section{Event-Related Potential Study}

3

4 Sonia Y Cárdenas ${ }^{1}$, Juan Silva-Pereyra ${ }^{2}$, Belén Prieto-Corona ${ }^{2}$, Susana A Castro-Chavira ${ }^{1}$, Thalía

5 Fernández ${ }^{1}$

6

$7{ }^{1}$ Departamento de Neurobiología Conductual y Cognitiva, Instituto de Neurobiología,

8 Universidad Nacional Autónoma de México, Campus Juriquilla, Querétaro 76230, México.

$9{ }^{2}$ Facultad de Estudios Superiores Iztacala, Universidad Nacional Autónoma de México,

10 Tlalnepantla, Estado de México 54090, México.

CORRESPONDING AUTHOR:

Dra. Thalía Fernández

17 Laboratorio de Psicofisiología, Departamento de Neurobiología Conductual y Cognitiva,

18 Instituto de Neurobiología, Universidad Nacional Autónoma de México,

19 Campus Juriquilla, Boulevard Juriquilla 3001, Querétaro 76230, México.

20 Email address: thaliafh@yahoo.com.mx

21 ORCID: 0000-0002-2842-7773 


\section{ABSTRACT}

Introduction. Dyscalculia is a specific learning disorder that affects a person's ability to learn certain mathematical processes. Children with dyscalculia constitute a heterogeneous group, partly due to the variability in their working memory. In this study, we used both behavioural responses and event-related potentials (ERPs) to explore arithmetic processing in children with dyscalculia and children with good academic performance by assessing ERPs during an addition verification task and examining whether these were associated with working memory

\section{1 (WM).}

Materials \& Methods. ERPs synchronised with congruent and incongruent probes were obtained in 22 children with dyscalculia (DYS group) and 22 children with good academic performance (GAP group) while they performed an addition verification task. The arithmetic N400 and late positive component (LPC) effects were defined by significant differences between the corresponding wave amplitudes for incongruent and congruent probes. Accuracy and speed of the behavioural responses were compared between groups by using mixed analyses of variance (ANOVAs) and ERP amplitudes were analysed using multivariate nonparametric permutation tests and correlation analyses. In subsequent analyses, the DYS group was divided into two subgroups: one with average WM indices and the other with lower-than-average WM

41 indices, and differences between these subgroups were explored.

42 Results. Participants in the GAP group obtained more correct answers than those in the DYS group, but no intergroup differences were observed in the response times. An arithmetic N400

44 effect was observed in the GAP group but not in the DYS group. Both groups displayed LPC

45 effects. In the DYS group, the larger the LPC effect was, the higher the working memory index. 
46 The two subgroups of the DYS group displayed different ERP patterns: while children with

47 dyscalculia and an average WM index showed a similar ERP pattern to children with good

48 academic performance, those with dyscalculia and a low WM index showed an atypical ERP

49 pattern.

50 Discussion. The results indicated that the group of children with dyscalculia was very

51 heterogeneous. The absence of an arithmetic N400 effect in these children suggests that the

52 processing at this stage was not useful enough to calculate and identify the correct result of the

53 operation; thus, a re-evaluation of the arithmetic-calculation process (that elicits an LPC effect)

54 was necessary in order to deliver a correct answer. Some of the children with dyscalculia had

55 WM deficits. The atypical ERP pattern shown by children with dyscalculia and WM deficits

56 reflects their difficulties in mathematical processing.

57 Conclusion. Since dyscalculia is a very heterogeneous deficit, studies examining dyscalculia

58 should consider exploring deficits in WM because these deficits may affect their calculation

59 process.

60

61 
63

64

65

66

67

\section{Introduction}

According to the Diagnostic and Statistical Manual of Mental Disorders, 5th Edition (DSM-5; American Psychiatric Association, 2013), dyscalculia refers to difficulties with number sense, number facts, and calculation (i.e., having a poor understanding of numbers, their magnitudes and relationships, counting on fingers to add single-digit numbers instead of recalling math facts as peers do, becoming lost in the midst of arithmetic computation, and switching procedures). The academic skills of children with dyscalculia are substantially below those expected for their chronological age, which can cause significant difficulties in academic performance and in activities of daily living (American Psychiatric Association, 2013). Dyscalculia cannot be better accounted for by intellectual disabilities, uncorrected visual or auditory acuity, other mental or neurological disorders, psychosocial adversity, lack of proficiency in the language of academic instruction, or inadequate educational instruction (American Psychiatric Association, 2013).

Dyscalculia is a heterogeneous cognitive disorder (Kaufmann et al., 2013). A known source of this heterogeneity is working memory (WM), which varies markedly between children with dyscalculia (Andersson \& Lyxell, 2007; Geary, 1993; Mammarella et al., 2017). The WM system provides online storage of information and its subsequent manipulation through four subsystems: the phonological loop, the visuospatial sketchpad, the episodic buffer, and the central executive (Baddeley, 2006). In the domain of mathematics, the phonological loop holds intermediate arithmetic results in the form of linguistic information, and plays a role in mathematical abilities that involve the articulation of numbers, such as counting, problemsolving, and arithmetic fact retrieval (Geary, 1993; Shen et al., 2018). The visuospatial sketchpad supports the construction of visual representations of numerical information and is, thus, related to spatial aspects of calculation, such as decomposition strategies (Foley et al., 2017; Simms et 
86 al., 2016). The episodic buffer provides a temporary storage that links information from the two

87 slave subsystems and long-term memory, allowing the maintenance of multi-code number

88 representations (Camos, 2018). Finally, the central executive coordinates and monitors

89 simultaneous processing and keeps track of math tasks that have already been performed

90 (DeStefano \& LeFrevre, 2004; Fuchs et al., 2005; Holmes \& Adams, 2006). Children with

91 dyscalculia may show difficulty in verbal short-term memory and verbal WM (Attout \&

92 Majerus, 2015; Berninger, 2008; Hitch \& McAuley, 1991; Peng \& Fuchs, 2016; Shen et al.,

93 2018; Swanson \& Siegel, 2001), visuospatial short-term memory and visuospatial WM (McDonald

94 \& Berg, 2018; Mammarella et al., 2017; Rotzer et al., 2009; Schuchardt et al., 2008), and the

95 central executive (Andersson \& Lyxell, 2007; Meyer et al., 2010; Vanbinst \& De Smedt, 2016).

96 In addition, these children have been reported to show a slower processing speed (Geary et al.,

97 1999; Landerl et al., 2004; Shalev et al., 2005).

98 Behavioural performance (accuracy and response time) in arithmetic tasks depends on the

99 arithmetic ability of the subject (Cipora \& Nuerk, 2013; LeFevre \& Kulak, 1994; Núñez-Peña \&

100 Suárez-Pellicioni, 2012) as well as individual characteristics such as age (De Smedt et al., 2009;

101 Geary \& Wiley, 1991; Geary et al., 1992) and school grade (Geary, 2004; Imbo \& Vandierendock,

102 2008). Behavioural performance also depends on the task features. In an arithmetic verification

103 task, in which the arithmetic operation (context) is followed by a possible solution (probe) that

104 may or may not match the correct result of the operation, the priming phenomenon manifests as a

105 shorter response time in the presence of facilitation provided by the context, i.e., when the probe

106 digit coincides with the result of the proposed arithmetic operation (congruent condition). One

107 explanation for this phenomenon is that the congruent solution is more quickly recovered from

108 memory (Niedeggen \& Rösler, 1999; Niedeggen et al., 1999). Thus, to provide a correct answer, 
109 a child needs to perform adequate arithmetic processing (to choose the correct probe) as well as

110 adequately maintain the result in verbal WM via the verbal short-term memory, which leads to

111 facilitation.

112 All previously mentioned studies used behavioural variables to draw their conclusions. Although

113 behavioural assessments of performance during tasks can yield data for variables such as

114 response time and percentage of correct answers, they ignore the subject's cerebral and cognitive

115 processes. In contrast, the high temporal resolution of event-related potentials (ERPs) can

116 elucidate these processes by representing the processing through each millisecond and thereby

117 allowing chronologic analysis of brain function through different cognitive processes.

118 ERPs have previously been used to study arithmetic processing. Evaluation of arithmetic

119 verification processing in healthy young adults by using ERPs reported a negative wave with

120 greater amplitude in an incongruent condition (i.e., when there is no facilitation provided by the

121 context) than in a congruent condition (i.e., with facilitation provided by the context) (Dong et al.,

122 2007; El Yagoubi et al., 2003; Hinault \& Lemaire, 2016; Prieto-Corona et al., 2010; Szücs \&

123 Csépe, 2005). The arithmetic N400 component is a negative waveform that begins at around 250

$124 \mathrm{~ms}$, peaks at around $400 \mathrm{~ms}$, and is maximal over the centroparietal area on the scalp (Dickson \&

125 Federmeier, 2017; Hinault \& Lemaire, 2016; Jost et al., 2004; Niedeggen et al., 1999;

126 Niedeggen \& Rösler, 1999; Prieto-Corona et al., 2010). If the arithmetic N400 component in

127 the incongruent is larger than in the congruent condition, the significant difference in amplitude

128 between these components is known as the arithmetic N400 effect, which reflects the strength of

129 the probe's relationship with the context (i.e., arithmetic operation) (Niedeggen \& Rösler, 1999).

$130 \mathrm{~N} 400$ is thought to reflect the automatic retrieval of arithmetic facts from long-term memory and

131 its magnitude represents the strength of the probe's relationship with the context (i.e., arithmetic 
132 operation) (Niedeggen \& Rösler, 1999). However, lack of concordance between automatic

133 recovery of the correct results and the probe may involve additional inhibitory processes (Hinault

134 \& Lemaire, 2016).

135 Studies with different populations have indicated that the arithmetic N400 effect is modulated by

136 arithmetic abilities. For example, the effect is greater in adults or teenagers with better arithmetic

137 abilities than in adults or teenagers, respectively, with poorer arithmetic abilities (Núñez-Peña et

138 al., 2011; Núñez-Peña \& Suárez-Pellicioni, 2012; 2015; Soltész et al., 2007; Soltész \& Szücs,

139 2009; Thevenot et al., 2007). Comparisons between children and adults have revealed differences

140 in latency and topographical distributions of the arithmetic N400 effect (Prieto-Corona et al., 2010).

141 Further, younger children show longer latencies than older children (Dong et al., 2007).

142 Another ERP component that has been used to investigate arithmetic processing in adults and

143 children is the late positive component (LPC). This follows the arithmetic N400 component,

144 appearing between 500 and $700 \mathrm{~ms}$. The LPC is a positive deflection in the ERP waveform that

145 shows a parietal (Jasinski \& Coch, 2012; Niedeggen \& Rösler; Núñez-Peña \& Suárez-Pellicioni,

146 2015; Xuan et al., 2007) or centro-parietal (Núñez-Peña \& Escera, 2007; Núñez-Peña \& Suárez-

147 Pellicioni, 2012; Prieto-Corona et al., 2010) topography, mainly over the right hemisphere

148 (Jasinski \& Coch, 2012; Niedeggen \& Rösler, 1999; Niedeggen et al., 1999). The significant

149 difference in amplitudes between LPC components elicited by incongruent and congruent

150 conditions is known as the LPC effect when amplitude in an incongruent condition is larger than

151 in a congruent condition (Jost et al., 2004; Niedeggen et al., 1999; Núñez-Peña \& Suárez-

152 Pellicioni, 2012; Prieto-Corona et al., 2010; Szücs \& Csépe, 2005; Szücs \& Soltész, 2010). The

153 LPC effect is associated with processing re-evaluation (Núñez-Peña \& Suárez-Pellicioni, 2012;

154 Prieto-Corona et al., 2010; Szücs \& Soltész, 2010), and its amplitude is modulated by the 
155 plausibility of a presented condition (Niedeggen \& Rösler, 1999; Núñez-Peña \& Escera, 2007;

156 Núñez-Peña \& Honrubia-Serrano, 2004; Núñez-Peña \& Suárez-Pellicioni, 2015; Szűcs \&

157 Soltész, 2010). Some authors have proposed that the LPC effect reflects surprise due to an out-

158 of-context stimulus (Donchin \& Coles, 1997; Núñez-Peña \& Suárez-Pellicioni, 2012; Polich,

159 2007). The LPC effect is greater in adults than in children (Zhou et al., 2011) and in individuals

160 with better arithmetic abilities than in those with arithmetic deficits (Iguchi \& Hashimoto, 2000;

161 Núñez-Peña et al., 2011; Núñez-Peña \& Honrubia-Serrano, 2004; Núñez-Peña \& Suárez-

162 Pellicioni, 2012; 2015; Szücs \& Soltész, 2010).

163 In summary, children with dyscalculia may show deficits in WM in addition to the characteristic

164 mathematical problems, making them a heterogeneous group. Although ERPs have shown that

165 neural processing in these children differs from that in children with typical abilities, the effects

166 of an additional WM deficit on the processing of an arithmetic verification task at the neural

167 level remain unknown. Since ERPs can reveal or highlight mechanisms that remain undetected

168 by behavioural measures, the body of knowledge about dyscalculia may be enhanced by

169 comparing ERPs of children with dyscalculia and those with typical development while the

170 children perform an arithmetic verification task. Thus, the first aim of the current study was to

171 compare the arithmetic processing between children with dyscalculia and children with good

172 academic performance by assessing their ERPs during an addition verification task. The second

173 aim was to explore the relationship between WM and ERPs in children with dyscalculia. We

174 hypothesised that, in comparison with children with good academic performance, children with

175 dyscalculia would show (1) less accurate or slower behavioural responses on an arithmetic

176 verification task, (2) smaller or later arithmetic N400 and LPC effects, and (3) poorer

177 performance on WM tests. In addition, we explored the possibility of a relationship between WM 
178 performance and the N400 and LPC effects in children with dyscalculia.

\section{Methods}

181

\subsection{Ethics}

182 This research was conducted in accordance with the ethical principles of the Declaration of

183 Helsinki. The Bioethics Committee of the Neurobiology Institute at the Universidad Nacional

184 Autónoma de México approved the experimental protocol (INEU/SA/CB/145). Children and

185 their parents gave written informed consent to participate in this study.

187 Forty-four right-handed children aged between 9 and 11 years participated in this study. The

188 participants were selected from a sample of 167 children from public and private elementary

189 schools in Querétaro, México. The study was carried out in 2015-2016. The interview,

190 examinations and psychological and neuropsychological tests were administered around two

191 months before the ERPs. After completing a semi-structured interview, we excluded 16 children

192 due to low socioeconomic status (the mother had not completed elementary school and/or per

193 capita income was less than $100 \%$ of the minimum wage; Harmony et al., 1990) and two

194 children who presented with epilepsy. In addition, we excluded six children with intellectual

195 disability (i.e., IQ < 70; Wechsler Intelligence Scale for Children, 4th Edition, Spanish version;

196 Wechsler, 2007), 52 children who showed psychiatric disorders (i.e., ADHD, behaviour disorder,

197 and/or oppositional defiant disorder as identified with MiniKid (Ferrando et al., 1998) and

198 neuropsychiatric assessments), and two children with uncorrected hypoacusis were excluded as 
199 well.

200 The remaining 89 children completed the arithmetic subtest of the Child Neuropsychological

201 Assessment (Matute et al., 2005), which is standardised and includes norms for the Mexican

202 population. Its arithmetic domain consists of three subdomains (counting, number management,

203 and calculus). Thirty participants who performed at or below the 9th percentile in at least one

204 arithmetic subdomain were assigned to a group of children with dyscalculia (DYS group), and 28

205 participants at or above the 37 th percentiles in all subdomains were assigned to a group with

206 good academic performance (GAP group). The remaining 31 participants that did not belong to

207 either of these two groups were excluded. Of the selected children, five from the DYS group

208 and two from the GAP group were excluded because their correct answers were below the

209 chance level (58\%). Another three children from the DYS group and four from the GAP group

210 were later excluded due to poor ERP data (see the ERP section below). Thus, the DYS and

211 GAP groups were each represented by 22 participants (11 and 14 girls in the DYS and GAP

212 groups, respectively). The groups did not differ in age, gender $\left(\chi^{2}(1)=0.834, p=0.361\right)$, or

213 monthly family income per capita.

214 Both groups underwent assessments for the four neuropsychological indices of the Wechsler

215 Intelligence Scale for Children: verbal comprehension index, working memory index, processing

216 speed index, and perceptual reasoning index. The children in the GAP group had scores of 85 or

217 higher in all indices, while those in the DYS group showed significantly lower scores on all the

218 indices except the processing speed index, as shown in Table 1. Figure 1 shows the boxplots of

219 the arithmetic subtests of the Child Neuropsychological Assessment and the WM index of the

220 Wechsler Intelligence Scale for Children. All participants had normal or corrected-to-normal

221 visual acuity, and they did not present any history of neurological or psychiatric disorders. 
222 Children from both groups were selected from the same schools and were therefore from the

223 same educational environments.

224

225

226

227

228

229

230

231

232

233

234

235

236

237

238

239

240

241

242
- Please insert Table 1 -

- Please insert Fig. 1 -

2.3 Stimuli

Each trial of the task started with a warning stimulus (a right-pointed arrow), which was followed by an addition operation with two single-digit operands between 1 and 9. Each addition operation combined the two Arabic digits using the plus sign (+), resulting in 81 different addition operations. Every operation was presented once with each of the correct and incorrect results (congruent and incongruent conditions). The incorrect result was constructed by either adding 2 to the correct result (for 41 facts) or by subtracting 2 from it (for the remaining 40 facts).

\subsection{Arithmetic verification task}

Figure 2 illustrates the time chart of the task. In each of the 162 trials, a white warning stimulus was presented at the centre of the black screen for $200 \mathrm{~ms}$, followed by a black screen that lasted for $300 \mathrm{~ms}$. A white addition operation then appeared for $1500 \mathrm{~ms}$, followed by another black screen for $1500 \mathrm{~ms}$. Subsequently, a white number (probe stimulus) was presented for $1000 \mathrm{~ms}$ on a black screen, which either did or did not match the sum of the numbers (for the congruent or incongruent conditions, respectively). Finally, a black screen was presented for $500 \mathrm{~ms}$. Half of the trials were congruent and half incongruent. Trials were randomised and delivered by MindTracer 2.0 software (Neuronic Mexicana, S.A.; Mexico City, Mexico). 
2432.5 Procedure

244 Children were seated in a comfortable chair $70 \mathrm{~cm}$ from the computer screen in a sound-

245 attenuated dimly-lit Faraday recording chamber. The experiment began after a training period to

246 familiarise the children with the task, which consisted of 16 trials with feedback. This was

247 followed by 162 trials divided into four blocks (two with 40 and two with 41 trials). Blocks were

248 separated by 1-minute rest periods.

249 All children were instructed to relax and maintain their gaze towards the centre of the screen and

250 to avoid blinking when the probe stimulus appeared. They were asked to blink after the response

251 was given, just before the warning stimulus. The children were instructed to respond as quickly

252 and accurately as possible when the probe stimuli were presented. Half the children were

253 instructed to press the mouse key with the right thumb if they thought the probe was correct

254 (congruent condition) and with the left thumb if they thought it was incorrect (incongruent

255 condition). The other half of the children were instructed to do the opposite.

256 2.6 ERP acquisition and analysis

257 A 19-channel EEG ( $\mathrm{Ag} / \mathrm{AgCl}$ electrodes held in position with a cap according to the 10-20

258 International System; Electro-Cap ${ }^{\mathrm{TM}}$ International, Inc.; Ohio, USA), referenced to linked

259 earlobes (A1A2), was recorded using a MEDICID ${ }^{\mathrm{TM}}$ IV system (Neuronic S.A.; Mexico City,

260 Mexico) and a Track Walker v5.0 data system while the child was performing the task. The

261 bandwidth of the amplifiers was $0.5-50 \mathrm{~Hz}$, and the sampling frequency was $200 \mathrm{~Hz}$. Impedances

262 in all the recordings were maintained below $5 \mathrm{k} \Omega$. Electro-oculograms were recorded with

263 electrodes located on the superciliary arch and the external canthus of the right eye. 
264 ERPs were computed offline using 1000-ms EEG epochs from each subject in each experimental

265 condition. The epochs consisted of a baseline period that started $200 \mathrm{~ms}$ before the probe onset

266 and ended $800 \mathrm{~ms}$ after the probe onset. Baseline correction was performed using the 200-ms

267 pre-stimulus period. An EEG epoch was rejected if visual inspection revealed blinking or ocular

268 movements, electrical activity exceeding 100 microvolts, or amplifier blocking for more than 50

269 ms at any electrode site. Seven participants (three in the DYS group) had fewer than 20 artifact-

270 free trials per condition, so these participants were excluded. The number of EEG epochs per

271 condition was approximately equal per subject. On average, the DYS and GAP groups had 33

272 and 39 artifact-free epochs, respectively, for each condition. Accepted EEG epochs associated

273 with correct answers were averaged together to produce one ERP each for the congruent and

274 incongruent conditions for each child. The former was subtracted from the latter (i.e.,

275 incongruent minus congruent) to produce one ERP difference wave per child.

$276 \quad 2.7$ Statistical analysis

277 2.7.1 Behavioural data analysis

278 Statistical analyses of behavioural data were performed using the statistical program SPSS (IBM

279 Statistic 20, Chicago Illinois, USA). We conducted mixed 2-way ANOVAs for response times and

280 for correct answers. The percentage of correct answers was transformed by arcsine [square root

281 (percentage/100)] (Zar, 2010). Group (GAP, DYS) was included as the between-subjects factor,

282 and condition (congruent, incongruent) was included as the within-subjects factor. The least

283 significant differences method was used for post-hoc pairwise comparisons.

284 2.7.2 ERP data analysis 
285 Figure 3 shows the scheme of statistical analyses for the ERP data. All assessments were

286 performed using nonparametric tests with permutations (Galán et al., 1998) due to the

287 multiplicity of comparisons and dependent variables and the consequently increased probability

288 of type I errors (Luck, 2014). Analyses were carried out using eLORETA software (Pascual-

289 Marqui et al., 2011). Five thousand permutations were performed. Global significance for the

290 statistical test (i.e., significant p-value level considering all the electrodes) was reported as T max

291 and its extreme p-value. Because this statistical test is based on an empirical probability

292 distribution, extreme p-values were corrected by multiple comparisons.

\section{- Please insert Fig. 3 -}

294 Time windows of the ERP components are usually defined by the outcomes of previous studies.

295 However, most studies relevant to this experiment tested young adults, who have faster

296 processing than children. To determine appropriate time windows for the arithmetic N400 and

297 LPC effects in children, we performed a non-parametric permutation test to identify significant

298 differences between the ERP waveforms for congruent and incongruent conditions per time point

299 between -200 to $800 \mathrm{~ms}$ at all electrode sites (Fig. 3A). In each group of children, we defined the

300 time windows of the arithmetic N400 and LPC.

301 The next step was to explore the topography of the N400 and LPC effects per group across all

302 electrode sites (Fig. 3B). In addition, eLORETA was used to conduct three analyses that

303 compared the ERP difference waveforms (incongruent minus congruent) between the two groups

304 (GAP, DYS) (Fig. 3C). Five thousand permutations were performed. Significant t-values over

305 electrode sites are represented in colour maps (only t-values with $\mathrm{p}<0.05$ ).

306 We also used eLORETA to perform three correlation analyses in the DYS group between each 
307 ERP difference wave form and the WM index across all electrode sites (Fig. 3D). Five thousand

308 permutations were performed. Significance for the statistical test was reported ( $\mathrm{r}$ max and its

309 extreme p-value). Specific significant correlations (r value) over electrode sites are represented

310 in colour maps (only r-values with $\mathrm{p}<0.05$ ).

311 All statistical results for the ERPs were reported taking into consideration all 19 electrodes.

\section{3. Results}

314 3.1 Behavioural results

315 The behavioural results are shown in Fig. 4. The participants in the GAP group showed a

316 significantly higher percentage of correct answers than those in the DYS group $\left(F_{(1,42)}=27.39, \mathrm{p}\right.$

$\left.317<0.0001, \eta_{\mathrm{p}}^{2}=0.395\right)$. The percentage of correct answers in the incongruent condition was

318 significantly higher than that in the congruent condition $\left(F_{(1,42)}=8.67, \mathrm{p}=0.005, \eta_{\mathrm{p}}{ }^{2}=0.171\right)$,

319 independently of the group. No significant group by condition interaction was noted $(F<1)$.

320 The responses for all children were significantly faster in the congruent condition than in the

321 incongruent condition $\left(F_{(1,42)}=131.922, \mathrm{p}<0.0001, \eta_{\mathrm{p}}^{2}=0.759\right)$, but the response times were

322 not significantly different between the groups $(F<1)$. No significant group by condition

323 interaction $\left(F_{(1,42)}=1.114, \mathrm{p}=0.297, \eta_{\mathrm{p}}{ }^{2}=0.026\right)$ was observed for this assessment. This finding

324 could be attributed to the large age range of the participants, since the automation of solutions to

325 arithmetic problems is a developing process in children of these ages. We tested this possibility

326 by exploring the association between age and response time using Spearman rank correlation

327 analyses within groups. The GAP group showed significant negative correlations for congruent 
$328(\mathrm{r}=-0.57, \mathrm{p}=0.006)$ and incongruent $(\mathrm{r}=-0.60, \mathrm{p}=0.003)$ conditions; however, the DYS group

329 showed no significant correlations for any condition (congruent: $r=-0.29, p=0.195$;

330 incongruent: $\mathrm{r}=-0.22, \mathrm{p}=0.337)$.

332 3.2 Electrophysiological results

333 3.2.1 Time windows for the N400 and LPC effects in the DYS and GAP groups

334 The statistical results showed significant differences between conditions from 305 to $385 \mathrm{~ms}$ and

335 from 510 to $630 \mathrm{~ms}$ in the GAP group $(\mathrm{T} \max =-3.387$, extreme $\mathrm{p}=0.0004)$. Figures $5 \mathrm{~A}$ and $5 \mathrm{~B}$

336 show the topography of the significant differences in the first and second windows, which

337 correspond to the arithmetic N400 and LPC effects, respectively, in terms of their latency and

338 polarity (negative and positive, respectively). The LPC effect elicited by the GAP group was

339 named the LPC1 effect. The topographic distribution of both ERP effects corresponds with the

340 findings reported in previous studies in young adults. The arithmetic N400 effect was localised

341 over the frontal midline (Megías \& Macizo, 2016; Prieto-Corona et al., 2010) and left

342 centroparietal area (Avancini et al., 2014, 2015; Dickson \& Federmeier, 2017). The LPC effect

343 was observed over the centro-parieto-temporal area, mainly in the right hemisphere (Avancini et

344 al., 2015; Dickson \& Federmeier, 2017; Jasinski \& Coch, 2012; Niedeggen \& Rösler, 1999). In

345 contrast, the DYS group only displayed a significant difference between 680 and $700 \mathrm{~ms}$ (T max

$346=4.84$, extreme $\mathrm{p}=0.021$ ), as shown in Fig. $5 \mathrm{C}$, which could correspond to a late LPC effect

347 (named the LPC2 effect). 
349 The grand averages of the ERPs in the T3 and C3 electrodes in the two task conditions for both

350 groups are shown in Fig. 6. This figure clearly illustrates that the lack of arithmetic N400 effect

351 in the DYS group is not associated with a lack of response, but with similarly large amplitudes

352 for both arithmetic N400 components in each condition.

- Please insert Fig. 6 -

354

3.2.2 ERP difference waveforms in the DYS and GAP groups

355

356

357

358

359

360

361

362

363

364

Having identified appropriate time windows for the N400 and LPC effects in each group, three statistical analyses for independent samples were performed using the permutation technique (considering all electrodes) to compare the ERP difference waves in the GAP and DYS groups per time window identified (305-385 ms, 510-630 ms, and 680-700 ms). The GAP children showed a significantly larger amplitude for the arithmetic N400 effect over T5 (T max $=-3.58$, extreme $\mathrm{p}=0.007$ ) and a significantly larger LPC1 effect over Fp2 (global T $\max =3.01$, extreme $p=0.032$ ) than the DYS children. In the LPC2 time window, no differences between groups were observed $(\mathrm{T} \max =1.46$, extreme $\mathrm{p}=0.45)$. Figure 7 shows the statistical colour maps of the arithmetic N400 effect and LPC effect comparisons between the two groups (GAP vs. DYS).

\subsubsection{Associations between WM and ERPs}

The heterogeneity that characterises behavioural performance in dyscalculia (Kaufmann et al., 2013) is also likely reflected on ERPs since ERPs correspond to the brain processing that underlies performance, which indicates that data dispersion is higher in the DYS group. 
370 Moreover, the DYS group showed more outliers than the GAP group (Fig. 8). One source of this

371 heterogeneity has been proposed to be WM (Andersson \& Lyxell, 2007; Geary, 1993).

\section{- Please insert Fig. 8 -}

373 The children with dyscalculia were assessed according to their WM indices and distributed into

374 two subgroups: one with average WM indices (scores equal to 85 or higher; $n=13,6$ girls) and

375 the other with lower-than-average WM indices (scores $<85 ; \mathrm{n}=8,4$ girls). Figure 9 displays the

376 grand average of the difference wave for these two subgroups of children with dyscalculia, as

377 well as children with good academic performance. The children with dyscalculia and a low WM

378 index score seemed to show one N200 peak, one arithmetic N400 peak, and two LPC peaks,

379 representing an atypical ERP pattern for this task. In contrast, children with dyscalculia, but with

380 average WM index scores, showed a similar ERP pattern to children with good academic

381 performance.

382

- Please insert Fig. 9 -

383 For the children with dyscalculia, correlation analyses between the WM index scores and the

384 amplitude values of the difference wave at each electrode site were performed in every ERP

385 window. No significant correlation was found between the WM index and the difference wave in

386 the N400 window. However, in both LPC windows, significant positive correlations were found

387 between the WM index and LPC difference waves. In the LPC1 time window, a greater WM

388 index correlated with a greater amplitude in the LPC effect over $\mathrm{O} 2$ and $\mathrm{T} 6\left(\mathrm{r}_{\max }=0.68\right.$, extreme

$389 \mathrm{p}=0.0056)$ and, in the LPC2 time window, a greater WM index correlated with a greater

390 amplitude of the LPC effect over T6 $\left(r_{\max }=0.61\right.$, extreme $\left.\mathrm{p}=0.0178\right)$. Figure 10 shows

391 statistical colour maps for the correlations between the WM index and the LPC effects. 


\section{4. Discussion}

395 The first objective of this study was to compare arithmetic verification processing in children

396 with dyscalculia with that in children with good academic performance during an addition

397 verification task by using ERPs. To our knowledge, this is the first study to compare the ERPs of

398 these two populations of children. We expected poorer behavioural performance (lower

399 percentage of correct answers and/or longer response times) in the children with dyscalculia than

400 in the children with good academic performance. For the ERP patterns, we hypothesised that the

401 children with dyscalculia would display longer latencies and smaller arithmetic N400 and LPC

402 effects than the children with good academic performance.

403 4.1 Behavioural differences between the DYS and GAP groups

404 Our behavioural results partially confirmed our hypothesis. We observed a significantly lower

405 percentage of correct answers in the DYS group than in the GAP group. This result corroborates

406 the findings of other behavioural studies (Castro \& Reigosa, 2011; Geary, 1993; Geary et al.,

407 1992; 1999; Landerl et al., 2004). The poor performance of children with dyscalculia has been

408 explained by their use of procedural strategies such as counting on, counting all, and

409 decomposition, which are more prone to errors, instead of the long-term-memory retrieval

410 strategies that are used by children with typical arithmetic abilities when facing one-digit

411 addition problems (Geary, 2004). Unfortunately, in the present study, the strategies used were

412 not systematically recorded for each child. This constitutes a limitation of the study because it

413 precludes us from proving that the observed differences were attributable to the strategies used. 
414 On the other hand, there was no significant group difference in response times. This could be

415 explained by the high dispersion in the data in both groups, mainly in the DYS group (see Fig.

416 4). As expected, in the GAP group, older children showed shorter response times, perhaps

417 because the automation of arithmetic facts tested herein is still developing in that age range.

418 Interestingly, children with dyscalculia did not show this association of performance with age.

419 This may be because, independently of age-related maturational process, children with

420 dyscalculia experience problems in this automation process.

421 4.2 ERP differences between the DYS and GAP groups

$422 \quad 4.2 .1 \mathrm{~N} 400$ effect

423 Only the GAP group exhibited the arithmetic N400 effect (a higher amplitude for the incongruent

424 condition than for the congruent condition). This effect was observed over the left temporo-

425 parieto-occipital and right fronto-temporal regions and peaked earlier than $400 \mathrm{~ms}$. The findings

426 for the frontal region coincide with the topography observed in some studies in young adults

427 (Megías \& Macizo, 2016; Prieto-Corona et al., 2010) and the left posterior localisation coincides

428 with those found in other studies (Avancini et al., 2014, 2015; Dickson \& Federmeier, 2017).

429 This more-distributed effect in children corresponds with the findings reported by Prieto-Corona

430 et al. (2010), who observed that the N400 effect in children involves more cortical regions than

431 that in adults to perform the same task, and by Dong et al. (2007), who compared younger and

432 older children during the performance of arithmetic verification tasks.

433 Only a few studies have assessed these effects in children, and the majority of them used

434 different arithmetic operations, which activate different brain regions (Zhou et al., 2011).

435 Another point of difference from these studies is that we obtained ERPs time-locked to the onset 
436 of the probe stimuli, whereas almost all studies obtained ERPs time-locked to the arithmetic

437 problem or equation (Van Beek et al., 2014; Xuan et al., 2007). Only the study by Xuan et al.

438 (2007) shows the same characteristics as ours; however that study observed the N400 effect over

439 the vertex. One concern regarding ERP topography could be the use of non-parametric statistics

440 because they are not commonly used. However, Picton et al. (2000) has argued that this is a

441 better approach for ERP assessment than parametric analyses because it makes no assumptions

442 about the distribution of the data, and is especially useful in the analysis of multichannel scalp

443 distributions, as in our study. This is supported by Megías and Macizo (2016) who analysed their

444 ERP data by using parametric and nonparametric statistical analysis and obtained similar

445 findings with both methods, with the nonparametric permutations appearing to be more sensitive

446 to differences.

447 Since we are using an arithmetic verification task to evoke the ERPs, it is important to determine

448 which processes could manifest in it. Among the four processes involved in the arithmetic

449 verification task proposed by Avancini et al. (2015), two were controlled in our task: (1) the

450 number of congruent and incongruent probes was equal, so violations of strategic expectations

451 should not have manifested as ERP effects; and (2) precisely the same probe stimuli were used

452 for both conditions, so the physical characteristics of the visual stimuli would not have affected

453 the ERPs. The other two effects are the magnitude effect and the violation of the operands'

454 semantic constraints when an incongruent probe is shown. Although all the incongruent probes

455 were 2 units away from the correct solution in our paradigm, a magnitude effect may have been

456 present; therefore, the priming effect and the magnitude effect could be mixed. A stronger left

457 posterior effect related to distance was observed by Avancini et al. (2014), consistent with the

458 studies indicating the association of this area with the verbal code according to the triple-code 
459 model (Dehaen \& Cohen, 1996). In our study, the GAP group showed a higher N400 effect than

460 the DYS group precisely in the left posterior temporal area (Fig. 8).

461 In contrast, children with dyscalculia showed no significant arithmetic N400 effect, and when

462 their ERPs were compared to those of the controls, significant differences were observed over

463 the left posterior temporal region. This finding is consistent with those of studies reporting a

464 smaller arithmetic N400 effect in adults or teenagers with dyscalculia compared to age-matched

465 controls (Núñez-Peña \& Suárez-Pellicioni, 2012; Soltész et al., 2007). The lack of a significant

466 N400 effect in children with dyscalculia could be explained as a failure to process congruent

467 results. In these children, any probe (congruent or incongruent) is perceived as a mismatch with

468 what is stored in the arithmetic lexicon (in Fig. 6, a negative deflection is elicited in both

469 conditions). Thus, they must revert to conducting the arithmetic calculation. The group

470 differences in the left temporal region may reflect the fact that simple addition problems

471 activate phonological processes, as has been described for multiplication problems (Zhou et al., 472 2009).

\section{$473 \quad 4.2 .2 \mathrm{LPC}$ effect}

474 The LPC effect was displayed in both groups, but with different latencies and topographies. The 475 DYS group showed a delayed LPC effect of shorter duration. Since the LPC effect is modulated

476 by the expectation or plausibility of the solution and children with dyscalculia had lower

477 arithmetic abilities, we expected a smaller LPC effect in the DYS group than in the GAP group.

478 Our results support this hypothesis because a significantly lower amplitude of the LPC effect was

479 observed in the DYS group in the right frontopolar region. Like other studies (Iguchi \&

480 Hashimoto, 2000; Núñez-Peña et al., 2011; Núñez-Peña \& Honrubia-Serrano, 2004; Núñez-Peña 
481 \& Suárez-Pellicioni, 2012; 2015; Szücs \& Soltész, 2010), we observed that the LPC effect is

482 greater in individuals with better performance, and that this difference was located in the right

483 frontal region. Meiri et al. (2012), who used functional near-infrared spectroscopy, observed that

484 the right frontal region is activated during simple additions, and this region is believed to be

485 responsible for holistic arithmetic processing (Dehaen et al., 2003; El Yagoubi et al., 2003). This

486 suggests that children in the GAP group perform a greater re-evaluation of incorrectness when

487 the proposed result was incongruent than when it was congruent, while children with dyscalculia,

488 perhaps due to the lack of arithmetic knowledge, re-evaluated almost all the results without

489 distinction between congruent and incongruent conditions.

490 Differences in topography were also observed between groups: The GAP group showed the LPC

491 effect in the expected right posterior location, while the DYS group exhibited this effect in the

492 left posterior region (see Fig. 5). The right lateralisation of the LPC effect in children with

493 good academic performance is consistent with the more deliberative and prolonged role of the

494 right hemisphere during probe evaluation, which has been found in adults during a

495 multiplication verification task (Dickson \& Federmeier, 2017). According to these authors,

496 after an initial period of evaluation of the provided response (probe), the left hemisphere

497 classifies it as correct or incorrect and no longer performs follow-up evaluations, while the

498 right hemisphere engages in a deliberate assessment of the additional features of the probe,

499 perhaps using spatial skills, to provide an evaluation that is less categorical. It is therefore

500 possible that children with dyscalculia intentionally search for the correct answer from their

501 long-term memory (left hemisphere), but failing to find the answer, they then perform the

502 arithmetic calculation. Although the topography recorded from the scalp does not necessarily

503 indicate the generators' location, different topographies indicate the presence of distinct 
504 generators (Nunez \& Srinivasan, 2006). Our results may suggest that the left lateralisation of

505 the LPC effect observed in children with dyscalculia is a compensatory phenomenon to obtain

506 the correct answer.

507 4.3 Heterogeneity within the DYS group

508 In contrast to our expectations, we found few differences between groups in the arithmetic N400

509 and LPC effects. The heterogeneity in the children's behaviour (Fig. 1 and Fig. 4), which was

510 enhanced in the WM behavioural scores (Fig. 1.B), and ERP patterns (Fig. 7) of the DYS group,

511 could explain this finding. Two main hypotheses have been proposed to explain atypical brain

512 functioning that is reflected as neurobiological disorders of cognitive processing (Silver et al.,

513 2008) that underlie learning disorders (Landerl et al., 2009). In addition to the domain-specific

514 hypothesis, which refers to abilities specifically related to mathematical competencies, the

515 common-deficit hypothesis postulates that certain processing patterns are common to all children

516 with learning disorders. Supporting this hypothesis, Swanson (1987) proposed that children with

517 learning disorders experience failures in executive functioning mechanisms, which also points to

518 WM deficits as essential problems (Berninger, 2008; Swanson, 2015; Swanson \& Siegel, 2001).

519 In children with arithmetic disabilities, WM has been frequently reported to play an essential role

520 in the arithmetic domain (Swanson, 2015). In our study, once children had performed the

521 addition operation, they had to store the result in WM until the probe digit appeared (1500 ms

522 later) to perform the response verification process and finally provide an answer. Therefore, the

523 arithmetic verification task that we used is particularly efficient for highlighting WM problems.

524 4.4 Working memory and dyscalculia

525 Consistent with our hypothesis, the children with dyscalculia showed a lower WM index than 
526 those in the GAP group. This finding aligns with previous studies where WM was found to

527 predict learning arithmetic (Meyer et al., 2010; Vanbinst \& De Smedt, 2016), as well as a

528 study by Mammarella et al. (2017), which reported that children with dyscalculia had low

529 scores for WM. Since the arithmetic N400 effect reflects a facilitation for the probe stimulus that

530 matches the correct answer, it may be the case that the absence of this effect is associated with

531 poor WM. Keeping the information of the addition in WM, as children with good academic

532 performance likely do, facilitates recognition or rejection of the proposed result.

533 However, it is important to emphasise that the WM performance in the DYS group was not

534 homogeneous. And while exploring the relationship between WM and arithmetic processing in

535 the DYS group, we discovered that children with higher WM index scores showed a greater

536 amplitude of the LPC effect in the right posterior region. This region coincides with the LPC

537 topography observed in previous studies (Niedeggen \& Rösler, 1999; Núñez-Peña \& Escera,

538 2007; Núñez-Peña \& Honrubia-Serrano, 2004) and in our control participants.

539 This relationship between WM and the LPC effect was elucidated in the present study and

540 contributes to the understanding of dyscalculia in children. For a more thorough exploration of

541 the WM effect in children with dyscalculia, children in the DYS group were classified into two

542 groups (average and lower-than-average) according to their WM index. Visual inspection of ERP

543 patterns from these two groups showed that the children with dyscalculia and an average WM

544 index had a similar ERP pattern to that in the children with good academic performance, while

545 the children with dyscalculia and a lower-than-average WM index showed an atypical ERP

546 pattern (Fig. 9). Visual inspection of the ERPs suggests that this atypical pattern consisted of two

547 negative peaks (at $195 \mathrm{~ms}$ and $405 \mathrm{~ms}$ ) over the parieto-occipital and centro-parieto-temporal

548 regions and two positive peaks (at $525 \mathrm{~ms}$ and $685 \mathrm{~ms}$ ) over the parietal regions. The two 
549 negativities could correspond to the N200 and arithmetic N400 effects, while the two positivities

550 may correspond to the two LPC effects. The N200 effect might be interpreted as evidence that

551 children with dyscalculia and poor WM engaged additional attentional resources (Xuan et al.,

552 2007). However, this N200 effect had a posterior topography; which may instead reflect a strong

553 early sensory attention (Schmajuk et al., 2006) before the comparison between the probe

554 stimulus and the sum result, which produces an arithmetic N400 effect. Later, the children

555 probably re-evaluated the arithmetic error (Núñez-Peña \& Suárez-Pellicioni, 2012) twice.

556 It is noteworthy that the categorisation of the ERP patterns of the DYS group into two subgroups

557 was based on visual inspection. Ideally, we would have compared the ERPs of the children with

558 dyscalculia with poor WM and typical WM statistically, but the sample sizes of these two

559 subgroups were too small. It would be useful if future studies could conduct these statistical

560 comparisons to help clarify whether the atypical ERP pattern that we observed is reliably

561 association with dyscalculia, poor WM, or both difficulties combined.

\section{5. Conclusions}

564 Children with dyscalculia did not show the arithmetic N400 effect found in children with typical

565 development during an arithmetic verification task; however, both groups showed an LPC effect.

566 The great heterogeneity within the group of children with dyscalculia precluded a robust LPC

567 effect in these children; however, the higher the WM deficits were, the lower the LPC effect was

568 in the right posterior region. In children with dyscalculia and WM deficits, an atypical ERP

569 pattern (i.e., N200, N400 and two LPC effects) was evinced. Therefore, future studies of both

570 working memory and ERPs in children with dyscalculia must be mindful of the heterogeneous 
571 nature of dyscalculia at both the level of behaviour and the brain function.

572

573 Acknowledgements:

574 The authors are grateful for the cooperation of the children and parents who participated in this

575 study. The authors also acknowledge the administrative support provided by Bertha Esquivel,

576 Iván Negrete, Leonor Casanova, Lourdes Lara, and Teresa Alvarez, and the technical assistance

577 provided by Benito Martínez-Briones, Daniel Villareal, Enrique Cabral, Héctor Belmont, Lucero

578 Albarrán-Cárdenas, María del Carmen Rodríguez, María Do Carmo Carvalho, María Elena

579 Juárez, Marisa Oar, Mauricio Cervantes-Romero, Milene Roca Stappung, Minerva Berenice

580 Rojas, Roberto Riveroll, Saulo Hernández, and Sergio Sánchez-Moguel. We also thank Angelica

581 Acosta for her comments on the manuscript.

583 Competing interest statement:

584 The authors declare that they have no competing interests.

586 Funding statement:

587 This work was supported by the Programa de Apoyo a Proyectos de Investigación e Innovación

588 Tecnológica (IN204613, IN205520, and IN207520) and the Consejo Nacional de Ciencia y

589 Tecnología (CONACYT; CB-2015-01-251309). Sonia Y Cárdenas is a beneficiary of the

590 CONACYT scholarship (No. 336175). 
592

593

594

595

596

597

598

599

600

601

602

603

604

605

606

607

608

609

610

611

612

613

614

615

616

617

618

619

620

621

622

623

American Psychiatric Association. 2013. Diagnostic and statistical manual of mental disorders, DSM-5, fifth ed. Washington: American Psychiatric Association.

Andersson U, Lyxell B. 2007. Working Memory deficits in children with mathematical difficulties: a general or specific deficit? Journal of Experimental Child Psychology 96:197-228 DOI:10.1016/j.jecp.2006.10.001.

Attout L, Majerus S. 2015. Working memory deficits in developmental dyscalculia: The importance of serial order. Child Neuropsychology 21:432-450

DOI:10.1080/09297049.2014.922170

Avancini C, Galfano G, Szücs D. 2014. Dissociation between arithmetic relatedness and distance effects is modulated by task properties: an ERP study comparing explicit vs. implicit arithmetic processing. Biological Psychology 103:305-16 DOI:10.1016/j.biopsycho.2014.10.003.

Avancini C, Soltész F, Szúcs D. 2015. Separating stages of arithmetic verification: An ERP study with a novel paradigm. Neuropsychologia 75:322-329

DOI:10.1016/j.neuropsychologia.2015.06.016

Baddeley AD. 2006. Working memory: an overview. In: Pickering SJ, ed. Working Memory and Education. Burlington, MA: Academic Press, 517-552.

Berninger V. 2008. Defining and differentiating dysgraphia, dyslexia, and language. Learning disability within a working memory model. In: Mody M, Silliman E, eds. Brain, behavior, and learning in language and reading disorders. New York: The Guilford Press, 103-134.

Camos V. 2018. Do Not Forget Memory to Understand Mathematical Cognition. In: Henik A, Fias W, eds. Heterogeneity of Function in Numerical Cognition. London: Academic Press, 433-447. DOI: 10.1016/B978-0-12-811529-9.00020-0

Castro D, Reigosa V. 2001. Calibrando la línea numérica mental. Evidencias desde el desarrollo típico y atípico. Revista de Neuropsicología, Neuropsiquiatría y Neurociencias 11:17-31.

Cipora K, Nuerk HC. 2013. Is the SNARC effect related to the level of mathematics? No systematic relationship observed despite more power, more repetitions, and more direct assessment of arithmetic skill. Quartely Journal of Experimental Psychology 66:1974-1991 DOI:10.1080/17470218.2013.772215. 
624

625

626

627

628

629

630

631

632

633

634

635

636

637

638

639

640

641

642

643

644

645

646

647

648

649

650

651

652

653

654

655

656

657

658

659
Dehaene S, Cohen L. 1997. Cerebral pathways for calculation: double dissociation between rote verbal and quantitative knowledge of arithmetic. Cortex 33:219-250 DOI:10.1016/s0010-9452(08)70002-9

Dehaene S, Piazza M, Pinel P, Cohen L. 2003. Three parietal circuits for number processing. Cognitive neuropsychology 20:487-506 DOI:10.1080/02643290244000239

De Smedt B, Janssen R, Bouwens K, Verschaffel L, Boets B, Ghesquière P. 2009. Working memory and individual differences in mathematics achievement: a longitudinal study from first grade to second grade. Journal of Experimental Child Psychology 103:186-201 DOI:10.1016/j.jecp.2009.01.004

DeStefano D, LeFevre JA. 2004. The role of working memory in mental arithmetic. European Journal of Cognitive Psychology 16:353-386 DOI:10.1080/09541440244000328

Dong X, Wang SH, Yang YL, Ren YL, Meng P, Yang YX. 2007. Zhonghua yi xue za zhi, 87:2825-2828.

Dickson DS, Federmeier KD. 2017. The language of arithmetic across the hemispheres: An event-related potential investigation. Brain Research 1662:46-56 DOI:10.1016/j.brainres.2017.02.019.

Donchin E, Coles MGH. 1997. Context updating and the P300. Behavioral and Brain Sciences 11:357-374 DOI:10.1017/S0140525X98230950.

El Yagoubi R, Lemaire P, Besson M. 2003. Different brain mechanisms mediate two strategies in arithmetic: Evidence from Event-Related brain Potentials. Neuropsychology 41:855-862 DOI:10.1016/S0028-3932(02)00180-X.

Ferrando L, Bobes J, Gilbert M, Soto M, Soto O. 1998. M.I.N.I. Mini International Neuropsychiatric Interview. Versión en español 5.0.0. DSM-IV. Instituto IAP Madrid.

Foley AE, Vasilyeva M, Laski EV. 2017. Children's use of decomposition strategies mediates the visuospatial memory and arithmetic accuracy relation. The British Journal of Developmental Psychology 35:303-309 DOI:10.1111/bjdp.12166.

Fuchs LS, Compton DL, Fuchs D, Paulsen K, Bryant JD, Hamlett CL. 2005. The prevention, identification, and cognitive determinants of math difficulty. Journal of Educational Psychology 97:493-513 DOI:10.1037/0022-0663.97.3.493.

Galán L, Biscay R, Rodríguez JL, Pérez-Abalo MC, Rodríguez R. 1998. Testing topographic differences between event related brain potentials by using nonparametric combinations of permutation tests. Electroencephalography and Clinical Neurophysiology 102:240-247 DOI:10.1016/s0013-4694(96)95155-3. 
660

661

662

663

664

665

666

667

668

669

670

671

672

673

674

675

676

677

678

679

680

681

682

683

684

685

686

687

688

689

690

691

692

693

694

695

696

697
Geary DC. 1993. Mathematical disabilities: cognitive, neuropsychological, and genetic components. Psychological Bulletin 114:345-362 DOI:10.1037/00332909.114.2.345.

Geary DC. 2004. Mathematics and learning disabilities. Journal of Learning Disabilities 37:4-15 DOI:10.1177/00222194040370010201.

Geary DC, Bow-Thomas CC, Yao Y. 1992. Counting knowledge and skill in cognitive addition: A comparison of normal and mathematically disabled children. Journal of Experimental Child Psychology 54:372-391 DOI:10.1016/00220965(92)90026-3.

Geary DC, Hoard MK, Hamson CO. 1999. Numerical and arithmetical cognition: Patterns of functions and deficits in children at risk for a mathematical disability. Journal of Experimental Child Psychology 74:213-239 DOI:10.1006/jecp.1999.2515.

Geary DC, Wiley JG. 1991. Cognitive addition: Strategy choice and speed-of-processing differences in young and elderly adults. Psychology and Aging 6:474 DOI:10.1037/0882-7974.6.3.474.

Harmony T, Marosi E, Díaz de León AE, Becker J, Fernández T. 1990. Effect of sex, psychosocial disadvantages and biological risk factors on EEG maturation. Electroencephalography and Clinical Neurophysiology 75:482-491 DOI:10.1016/0013-4694(90)90135-7.

Hinault T, Lemaire P. 2016. What does EEG tell us about arithmetic strategies? A review. International Journal of Psychophysiology 106:115-126 DOI:10.1016/j.ijpsycho.2016.05.006.

Hitch GJ, McAuley E. 1991. Working memory in children with specific arithmetical learning difficulties. British Journal of Psychology 82:375-386 DOI: 10.1111/j.2044-8295.1991.tb02406.x.

Holmes J, Adams JW. 2006. Working Memory and Children's Mathematical Skills: Implications for mathematical development and mathematics curricula. Educational Psychology 26:339-366 DOI:10.1080/01443410500341056

Iguchi Y, Hashimoto I. 2000. Sequential information processing during a mental arithmetic is reflected in the time course of event-related brain potentials. Clinical Neurophysiology 111:204-213 DOI:10.1016/S1388-2457(99)00244-8.

Imbo I, Vandierendock A. 2008. Effects of problem size, operation, and working-memory span on simple-arithmetic strategies: differences between children and adults? Psychological Research 72:331-346 DOI:10.1007/s00426-007-0112-8.

Jasinski EC, Coch D. 2012. ERPs across arithmetic operations in a delayed answer verification task. Psychophysiology 49:943-958 DOI:10.1111/j.14698986.2012.01378.x 
698

699

700

701

702

703

704

705

706

707

708

709

710

711

712

713

714

715

716

717

718

719

720

721

722

723

724

725

726

727

728

729

730

731

732

733

734

735
Jost K, Hennighausen E, Rösler F. 2004. Comparing arithmetic and semantic fact retrieval: Effects of problem size and sentence constraint on event-related brain potentials. Psychophysiology 41:46-59 DOI:10.1111/1469-8986.00119_41_1.

Kaufmann L, Mazzocco MM, Dowker A, von Aster M, Göbel SM, Grabner RH, Henik A, Jordan NC, Karmiloff-Smith AD, Kucian K, Rubinsten O, Szucs D, Shalev R, Nuerk HC. 2013. Dyscalculia from a developmental and differential perspective. Frontiers in Psychology 4:516. doi: 10.3389/fpsyg.2013.00516.

Landerl K, Bevan A, Butterworth B. 2004. Developmental dyscalculia and basic numerical capacities: a study of 8-9-year-old students. Cognition 93:99-125 DOI:10.1016/j.cognition.2003.11.004.

Landerl K, Fussenegger B, Moll K, Willburger E.2009. Dyslexia and dyscalculia: two learning disorders with different cognitive profiles. Journal of Experimental Child Psychology 103: 309-324 DOI:10.1016/j.jecp.2009.03.006.

LeFevre JA, Kulak AG. 1994. Individual differences in the obligatory activation of addition facts. Memory and Cognition 22:188-220 DOI:10.3758/bf03208890.

Luck SJ. 2014. An Introduction to the Event-Related Potential Technique. Second Ed. Cambridge: MIT Press.

Mammarella IC, Caviola S, Giofrè D, Szücs D. 2017. The underlying structure of visuospatial working memory in children with mathematical learning disability. The British Journal of Developmental Psychology 36:220-235 DOI:10.1111/bjdp.12202.

Matute E, Rosselli M, Ardila A, Ostrosky-Solís F. 2013. Evaluación neuropsicológica infantil. Segunda Ed. México DF: Manual Moderno.

DOI:10.33588/rn.3808.2003400

McDonald PA, Berg DH. 2018. Identifying the nature of impairments in executive functioning and working memory of children with severe difficulties in arithmetic. Child Neuropsychology 24:1047-1062.

DOI:10.1080/09297049.2017.1377694

Megías P, Macizo P. 2016. Simple arithmetic: electrophysiological evidence of coactivation and selection of arithmetic facts. Experimental Brain Research 234:3305-3319 DOI:10.1007/s00221-016-4728-z980149

Meiri H, Sela I, Nesher P, Izzetoglu M, Izzetoglu K, Onaral B, Breznitz Z. 2012. Frontal lobe role in simple arithmetic calculations: an fNIR study. Neuroscience letters 510: 43-47_DOI:10.1016/j.neulet.2011.12.066

Meyer ML, Salimpoor VN, Wu SS, Geary DC, Menon V. 2010. Differential contribution of specific working memory components to mathematics achievement in 2nd and 3rd graders. Learning and Individual Differences 20:101-109

DOI:10.1016/j.lindif.2009.08.004. 
736

737

738

739

740

741

742

743

744

745

746

747

748

749

750

751

752

753

754

755

756

757

758

759

760

761

762

763

764

765

766

767

768

769

770

771

772

773
Niedeggen M, Rösler F. 1999. N400 Effects Reflect Activation Spread During Retrieval of Arithmetic Facts. Psychological Science 10:271-176 DOI:10.1111/14679280.00149 .

Niedeggen M, Rösler F, Jost K. 1999. Processing of incongruous mental calculation problems: Evidence for an arithmetic N400 effect. Psychophysiology 36:307-324 DOI:10.1017/s0048577299

Nunez PL \& Srinivasan R. 2006. Electrical fields of the brain. The Neurophysics of EEG. Oxford: Oxford University Press.

Núñez-Peña MI, Escera C. 2007. An event-related brain potential study of the arithmetic split effect. International Journal of Psychophysiology 64:165-173 DOI:10.1016/j.ijpsycho.2007.01.007.

Núñez-Peña MI, Gracia-Bafalluy M, Tubau E. 2011. Individual differences in arithmetic skill reflected in event-related brain potentials. International Journal of Psychophysiology 80:143-149 DOI:10.1016/j.ijpsycho.2011.02.017

Núñez-Peña MI, Honrubia-Serrano ML. 2004. P600 related to rule violation in an arithmetic task. Cognitive Brain Research 18:130-141 DOI:10.1016/j.cogbrainres.2003.09.010.

Núñez-Peña MI, Suárez-Pellicioni M. 2012. Processing false solutions in additions: differences between high-and lower-skilled arithmetic problem-solvers. Experimental Brain Research 218:655-663 DOI:10.1007/s00221-012-3058-z.

Núñez-Peña MI, Suárez-Pellicioni M. 2015. Processing of multi-digit additions in high math-anxious individuals: psychophysiological evidence. Frontiers in Psychology 6:1268 DOI:10.3389/fpsyg.2015.01268.

Pascual-Marqui RD, Lehmann D, Koukkou M, Kochi K, Anderer P, Saletu B, Tanaka H, Hirata K, John ER, Prichep L, Biscay-Lirio R, Kinoshita T. 2011. Assessing interactions in the brain with exact low-resolution electromagnetic tomography. Philosophical Transactions of the Royal Society A: Mathematical, Physical and Engineering Sciences 369:3768-3784 DOI:10.1098/rsta.2011.0081.

Peng P, Fuchs D. 2016. A Meta-Analysis of Working Memory Deficits in Children With Learning Difficulties: Is There a Difference Between Verbal Domain and Numerical Domain?. Journal of Learning Disabilities 49:3-20. DOI:10.1177/0022219414521667.

Picton TW, Bentin S, Berg P, Donchin E, Hillyard SA, Johnson R Jr, Miller GA, Ritter W, Ruchkin DS, Rugg MD, Taylor MJ. 2000. Guidelines for using human eventrelated potentials to study cognition: recording standards and publication criteria. Psychophysiology 37:127-152 DOI: 10.1111/1469-8986.3720127.

Polich J. 2007. Updating P300: an integrative theory of p3a and P3b. Clinical Neurophysiology 118:2128-2148 DOI:10.1016/j.clinph.2007.04.019. 
774

775

776

777

778

779

780

781

782

783

784

785

786

787

788

789

790

791

792

793

794

795

796

797

798

799

800

801

802

803

804

805

806

807

808

809

810

811

812
Prieto-Corona, Rodríguez-Camacho M, Silva-Pereyra J, Marosi E, Fernández T, Guerrero V. 2010. Event-related potentials findings differ between children and adults during arithmetic-fact retrieval. Neuroscience Letters 468:220-224 DOI: 10.1016/j.neulet.2009.10.094.

Rotzer S, Loenneker T, Kucian K, Martin E, Klaver P, von Aster M. 2009. Dysfunctional neural network of spatial working memory contributes to developmental dyscalculia. Neuropsychologia 47:2859-2865 DOI:10.1016/j.neuropsychologia.2009.06.009.

Schmajuk M, Liotti M, Busse L, Woldorff MG. 2006. Electrophysiological activity underlying inhibitory control processes in normal adults. Neuropsychologia 44:384-395 DOI:10.1016/j.neuropsychologia.2005.06.005

Schuchardt K, Maehler C, Hasselhorn M. 2008. Working memory deficits in children with specific learning disorders. Journal of Learning Disabilities 41:514-523 DOI:10.1177/0022219408317856.

Shalev RS, Manor O, Gross-Tsur V. 2005. Developmental dyscalculia: a prospective sixyear follow-up. Developmental medicine and child neurology, 47:121-125 DOI:10.1017/s0012162205000216

Shen I, Liu P, Chen C. 2018. Neural correlates underlying spatial and verbal working memory in children with different mathematics achievement levels: an EventRelated Potential study. International Journal of Psychophysiology 133: 149-158 DOI:10.1016/j.ijpsycho.2018.07.006

Silver CH, Ruff RM, Iverson GL, Barth JT, Broshek DK, Bush SS, Koffler SP, Reynolds CR, NAN Policy and Planning Committee. 2008. Learning disabilities: the need for neuropsychological evaluation. Archives of Clinical Neurophysiology 23:217219 DOI:10.1016/j.acn.2007.09.006.

Simms V, Clayton S, Cragg L, Gilmore C, Johnson S. 2016. Explaining the relationship between number line estimation and mathematical achievement: The role of visuomotor integration and visuospatial skills. Journal of Experimental Child Psychology 145:22-33 DOI:10.1016/j.jecp.2015.12.004.

Soltész F, Szücs D. 2009. An electro-physiological temporal principal component analysis of processing stages of number comparison in developmental dyscalculia. Cognitive Development 24:473-485 DOI:10.1016/j.cogdev.2009.09.002.

Soltész F, Szücs D, Dékány J, Márkus A, Csépe V. 2007. A combined event-related potential and neuropsychological investigation of developmental dyscalculia. Neuroscience Letters 417(2):181-186

DOI:10.1016/j.neulet.2007.02.067

Swanson HL. 1987. Information processing theory and learning disabilities: a commentary and future perspective. Journal of Learning Disabilities 20:155-166 DOI:10.1177/002221948702000303. 
813

814

815

816

817

818

819

820

821

822

823

824

825

826

827

828

829

830

831

832

833

834

835

836

837

838

839

840

841

842

843

844

845

846

847

848

849

850
Swanson HL. 2015. Intelligence, Working Memory, and Learning Disabilities. In: Papadopoulos TC, Parrila RK, and Kirby JR, eds. Cognition, Intelligence, and Achievement. Amsterdam: Academic Press, 175-196.

Swanson HL, Beebe-Frankenberger M. 2004. The relationship between working memory and mathematical problem solving in children at risk and not at risk for serious math difficulties. Journal of Educational Psychology 96:471-491

DOI:10.1037/0022-0663.96.3.471

Swanson HL, Siegel L. 2001. Learning disabilities as a working memory deficit. Issues in Education 7:1-48.

Szücs D. 2016. Subtypes and comorbidity in mathematical learning disabilities: Multidimensional study of verbal and visual memory processes is key to understanding. Progress in Brain Research 227:277-304

DOI:10.1016/bs.pbr.2016.04.027

Szücs D, Csépe V. 2005. The effect of numerical distance and stimulus probability on ERP components elicited by numerical incongruencies in mental addition. Cognitive Brain Research 22:289-300 DOI:10.1016/j.cogbrainres.2004.04.010.

Szücs D, Soltész F. 2010. Event-related brain potentials to violations of arithmetic syntax represented by place value structure. Biological Psychology 84:354-367 DOI:10.1016/j.biopsycho.2010.04.002.

Thevenot C, Fanget M, Fayol M. 2007. Retrieval or nonretrieval strategies in mental arithmetic? An operand recognition paradigm. Memory and Cognition 35:13441352 DOI:10.3758/bf03193606.

Träff U, Olsson L, Östergren R, Skagerlund K. 2020. Development of early domainspecific and domain-general cognitive precursors of high and low math achievers in grade 6. Child Neuropsychology 1-26 DOI:10.1080/09297049.2020.1739259.

Van Beek L, Ghesquière P, De Smedt B, Lagae L. 2014. The arithmetic problem size effect in children: an event-related potential study. Frontiers in Human Neuroscience 8:756 DOI:10.3389/fnhum.2014.00756.

Vanbinst K, De Smedt B. 2016. Individual differences in children's mathematics achievement: The roles of symbolic numerical magnitude processing and domain-general cognitive functions. Progress in Brain Research 227:105-130 DOI:10.1016/bs.pbr.2016.04.001

Wechsler D. 2007. Wechsler intelligence scale for children-WISC-IV. México DF: Manual Moderno. DOI:10.1016/j.neuroimage.2013.12.030.

Xuan D, Wang S, Yang Y, Meng P, Xu F, Yang W, Sheng W, Yang Y. 2007. Age difference in numeral recognition and calculation: an event-related potential study. Child Neuropsychology 13:1-17 DOI:10.1080/09297040600760465.

Zar JH. 2010. Biostatistical Analysis. New York: Prentice Hall International Inc. 
851

852

853

854

855

856

857

858

859

860
Zhou X, Booth JR, Lu J, Zhao H, Butterworth B, Chen C, Dong Q. 2011. Ageindependent and age-dependent neural substrate for single-digit multiplication and addition arithmetic problems. Developmental Neuropsychology 36:338-352 DOI:10.1080/87565641.2010.549873.

Zhou X, Chen C, Qiao S, Chen C, Chen L, Lu N, Dong Q. 2009. Event-related potentials for simple arithmetic in Arabic digits and Chinese number words: a study of the mental representation of arithmetic facts through notation and operation effects. Brain Research 1302:212-224 DOI:10.1016/j.brainres.2009.09.024 


\section{FIGURE CAPTIONS}

862 Fig. 1. Variability of arithmetic subdomains and WM index in both groups. (A) Box-and-

863 whisker plots of the subdomains (counting, number management, and calculus) of the arithmetic

864 subtest of the Child Neuropsychological Assessment in both groups of children (GAP and DYS).

865 (B) Box-and-whisker plots of the working memory index of the Wechsler Intelligence Scale for

866 Children, 4th Edition, Spanish version. The error bars represent the standard deviation.

867 Fig. 2. Depiction of a trial of the addition verification task. Flowchart of stimuli presentation

868 during individual trials, W: warning stimulus.

869 Fig. 3. Workflow of the statistical analyses of ERP data using non-parametric permutation

870

871

872

873

874

875

876

877

878

879

880

881

882

tests. (A) Definition of analysed time windows, where significant differences between incongruent and congruent conditions (effects) were evinced; comparison between conditions using multiple t-tests, shown at each point of time throughout the electrode sites (colour lines in the coordinate axis). Magenta horizontal lines represent the threshold of $t$-values for $p=0.05$, and grey shadowed boxes represent the analysed time windows where significant differences were found. Colour lines in the coordinate axis represent t-values at different electrode sites. (B) Exploration of the topography of ERP effects (incongruent minus congruent) obtained from (A); t- tests were computed using the mean amplitude values in each condition for each analysed time window (N400 and LPC in the group GAP and LPC in the group DYS) across all electrode sites. (C) Comparison of the ERP-difference wave between the DYS and GAP groups. Mean amplitude values of the difference waves were used to compute the t-tests. (D) Correlation analyses between the working memory index and ERP difference waves for the DYS group, for each electrode site and each ERP window. 
883 Fig. 4. Behavioural data in both groups of children (GAP and DYS) in the arithmetic

884 verification task. The correct answer (A) and mean response time (B) in both conditions

885 (congruent and incongruent) and both groups of children. Error bars represent the standard

886 deviation. The DYS group showed a lower percentage of correct answers than the GAP group.

$887 * * * \mathrm{p}<0.0001$

888 Fig. 5. Statistical parametric maps of the arithmetic N400 and LPC effects in both groups.

889 Top: GAP group. (A) Differences between conditions at 305 to $385 \mathrm{~ms}$ (arithmetic N400). (B)

890 Differences between conditions at 510 to $630 \mathrm{~ms}$ (LPC effect). Bottom: DYS group. (C)

891 Differences between conditions at 680 to $700 \mathrm{~ms}$ (LPC effect). Blue and red colours represent

892 the t-values that were above the threshold of significance $(\mathrm{p}<0.001)$. In the GAP group, the

893 arithmetic N400 effect was elicited at P3, O1, T4, T5, Fz, and Pz, and the LPC effect was elicited

894 at C4, P4, O1, O2, T4, T6, Cz, and Pz, while in the DYS group, the LPC effect was observed at

895 P3 and O1. All $\mathrm{p}<0.001$

896 Fig. 6. ERP wave grand averages. (A) T3 electrode. (B) C3 electrode. The GAP group

897 responses to congruent and incongruent conditions are represented by the black continuous and

898 discontinuous lines, while the DYS group responses to congruent and incongruent conditions are

899 represented by the red continuous and discontinuous lines, respectively. Negativity is plotted

900 downwards.

901 Fig. 7. Differences between groups in arithmetic N400 and LPC effects. (A) Statistical map

902 of the comparison between groups based on the difference between conditions (incongruent

903 minus congruent) for the arithmetic N400 (305-385 ms) at T5. (B) Statistical map of the

904 comparison between groups based on the difference between conditions (incongruent minus 
905 congruent) for the LPC (510-630 ms) at Fp2. The blue and red spots represent significant

906 differences between groups ( $\mathrm{t}-\mathrm{values} \mathrm{p}<0.05)$.

907 Fig. 8. Variability of arithmetic N400 and LPC effects. (A) Box-and-whisker plots of both

908 groups of children (GAP and DYS) using the amplitude values of the arithmetic N400 (305-385

$909 \mathrm{~ms}$ ) effect. (B) Box-and-whisker plots of both groups of children using the amplitude values of

910 the LPC (510-630 ms) effect.

911 Fig. 9. Grand averages of the difference waves (i.e., incongruent minus congruent

912 condition). Blue solid lines represent the ERPs for the GAP group. Red solid lines represent the

913 ERPs for the DYS group with high WM index scores and red dotted lines represent those for the

914 DYS group with low WM index scores. Positive is plotted up. The arithmetic N400 effect and

915 the LPC effect in the GAP group are marked with grey-shadow boxes. Black arrows indicate

916 double-negative peaks (195 ms and $405 \mathrm{~ms}$ ) and double-positive peaks (525 ms and $685 \mathrm{~ms}$ ) in

917 the DYS group with low WM scores at P3 and C3, but such effects can be observed over other

918 electrode sites. Each letter represents an electrode. (A) Fp1. (B) Fp2. (C) F3. (D) F4. (E) C3. (F)

919 C4. (G) P3. (H) P4. (I) O1. (J) O2. (K) F7. (L) F8. (M) T3. (N) T4. (O) T5. (P) T6. (Q) Fz. (R)

920 Cz. (S) Pz.

921 Fig. 10. Relationship between working memory and LPC effect in the DYS group. (A)

922 Statistical map of the correlations between the WM index and the ERP amplitude difference

923 between conditions (incongruent minus congruent) at 510 to $630 \mathrm{~ms}$ (LPC effect) across

924 electrode sites. The red spot represents the significant $r$ values $(p<0.05)$ over the T6 and O2

925 electrodes. (B) Ascending regression line showing that higher values of the working memory

926 index (X axis) are associated with greater LPC effects in the electrode T6 (Y axis). (C) 
927 Ascending regression line showing that higher values of the working memory index (X axis) are 928 associated with greater LPC effect in the electrode $\mathrm{O} 2$ (Y axis).

929

930 


\section{Table $\mathbf{1}$ (on next page)}

Differences between groups in terms of demographic features, arithmetic performance and intelligence quotient

ENI: Child Neuropsychological Assessment (Matute et al., 2005); WISC-IV: The Wechsler Intelligence Scale for Children, 4th Edition Spanish version (WISC-IV; Wechsler, 2007); GAP: children with good academic performance; DYS: children with dyscalculia. 


\begin{tabular}{|c|c|c|c|c|}
\hline & \multicolumn{2}{|l|}{ Mean \pm SD } & \multirow[t]{2}{*}{$\mathrm{t}(42)$} & \multirow[t]{2}{*}{ p-value } \\
\hline & GAP & DYS & & \\
\hline Age (years) & $9.41 \pm 1.182$ & $9.77 \pm 0.813$ & -1.189 & 0.241 \\
\hline Monthly economic income & $2421 \pm 1188.81$ & $1983 \pm 1209.76$ & 1.211 & 0.233 \\
\hline \multicolumn{5}{|c|}{ ENI subscales (arithmetic domain) } \\
\hline Counting & $65.27 \pm 15.03$ & $24.55 \pm 23.86$ & 6.772 & $<0.001$ \\
\hline Number management & $59.73 \pm 23.03$ & $13.91 \pm 17.68$ & 7.400 & $<0.001$ \\
\hline Calculus & $68.18 \pm 20.99$ & $20.91 \pm 26.08$ & 6.622 & $<0.001$ \\
\hline Logical mathematical reasoning & $68.45 \pm 22.28$ & $51.41 \pm 35.02$ & 1.926 & 0.061 \\
\hline \multicolumn{5}{|l|}{ WISC-IV indexes } \\
\hline Intelligence quotient & $105.95 \pm 10.86$ & $89.55 \pm 10.82$ & 5.017 & $<0.001$ \\
\hline Verbal comprehension index & $102.41 \pm 20.69$ & $86.23 \pm 21.62$ & 2.536 & 0.015 \\
\hline Perceptual reasoning index & $100.59 \pm 18.71$ & $85.68 \pm 20.83$ & 2.947 & 0.017 \\
\hline Working memory index & $104.23 \pm 11.48$ & $89.36 \pm 13.85$ & 3.875 & $<0.001$ \\
\hline Processing speed index & $97.95 \pm 20.71$ & $91.68 \pm 14.32$ & 1.168 & 0.249 \\
\hline \multicolumn{5}{|l|}{ WISC-IV subtests } \\
\hline Similarities & $10.77 \pm 2.72$ & $8.59 \pm 4.22$ & 2.035 & 0.048 \\
\hline Vocabulary & $11.64 \pm 2.82$ & $8.55 \pm 2.24$ & 4.024 & $<0.001$ \\
\hline Comprehension & $10.82 \pm 3.11$ & $8.09 \pm 2.87$ & 3.019 & 0.004 \\
\hline Block design & $10.86 \pm 2.76$ & $8.68 \pm 2.62$ & 2.684 & 0.010 \\
\hline Picture Concepts & $10.59 \pm 2.70$ & $8.86 \pm 2.66$ & 2.137 & 0.038 \\
\hline Matrix reasoning & $10.45 \pm 2.28$ & $8.41 \pm 1.91$ & 3.217 & 0.002 \\
\hline Digit span & $10.73 \pm 2.12$ & $7.68 \pm 2.41$ & 4.442 & $<0.001$ \\
\hline Letter-number sequencing & $11.23 \pm 2.20$ & $8.14 \pm 2.73$ & 4.133 & $<0.001$ \\
\hline Arithmetic & $14.00 \pm 3.14$ & $9.75 \pm 2.86$ & 4.417 & $<0.001$ \\
\hline Coding & $10.23 \pm 2.56$ & $8.64 \pm 1.94$ & 2.322 & 0.025 \\
\hline Symbol search & $10.41 \pm 2.21$ & $9.27 \pm 2.18$ & 1.711 & 0.094 \\
\hline
\end{tabular}




\section{Figure 1}

Variability of arithmetic subdomains and WM index in both groups.

(A) Box-and-whisker plots of the subdomains (counting, number management, and calculus)

of the arithmetic subtest of the Child Neuropsychological Assessment in both groups of children (GAP and DYS). (B) Box-and-whisker plots of the working memory index of the Wechsler Intelligence Scale for Children, 4th Edition, Spanish version. The error bars represent the standard deviation. 
A.

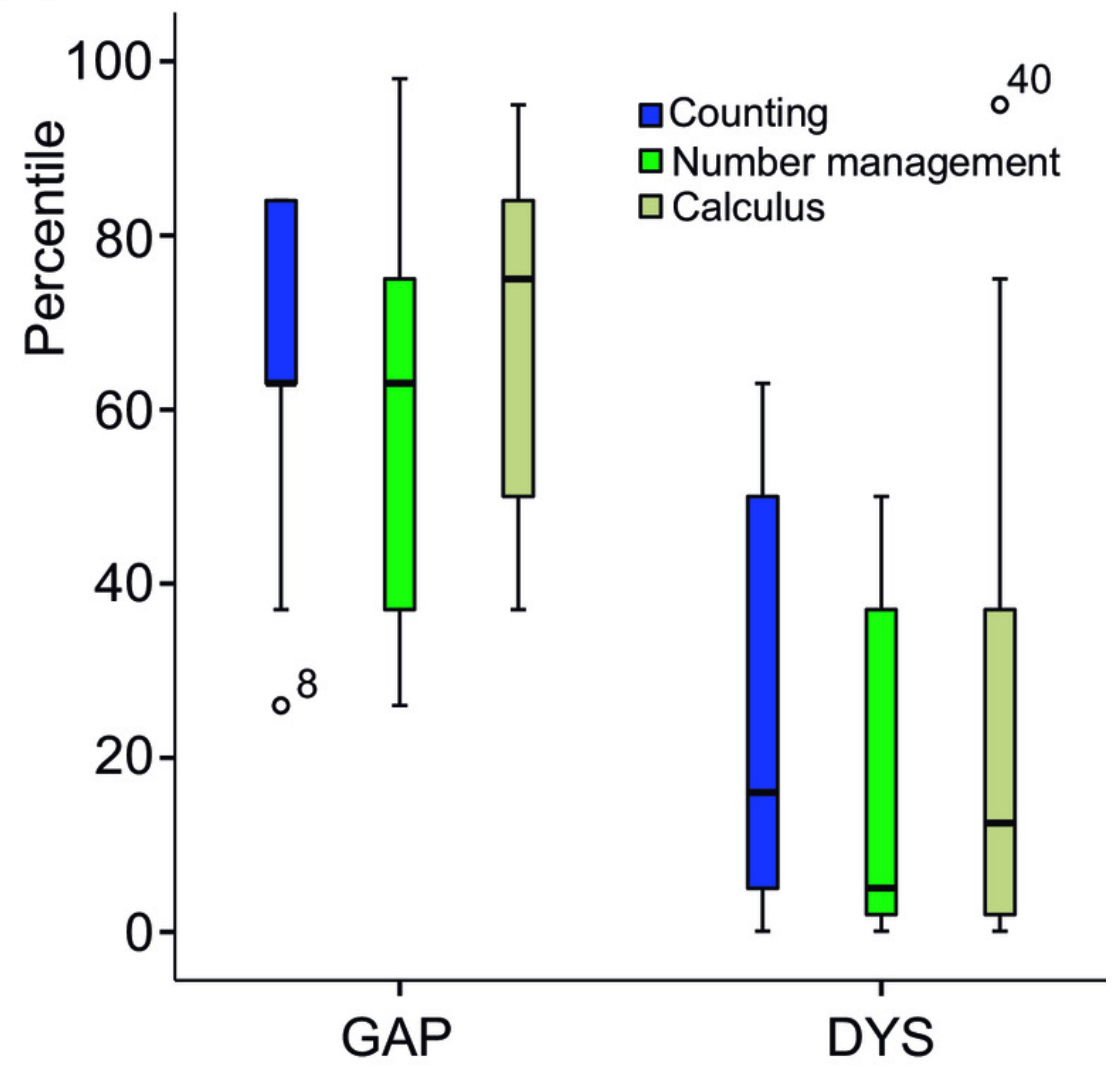

B.

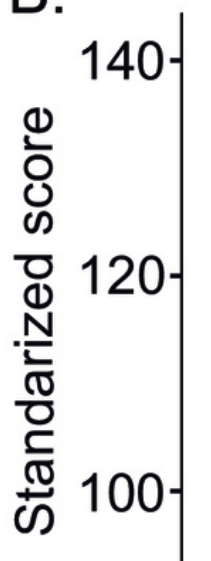

$\square$ WM index

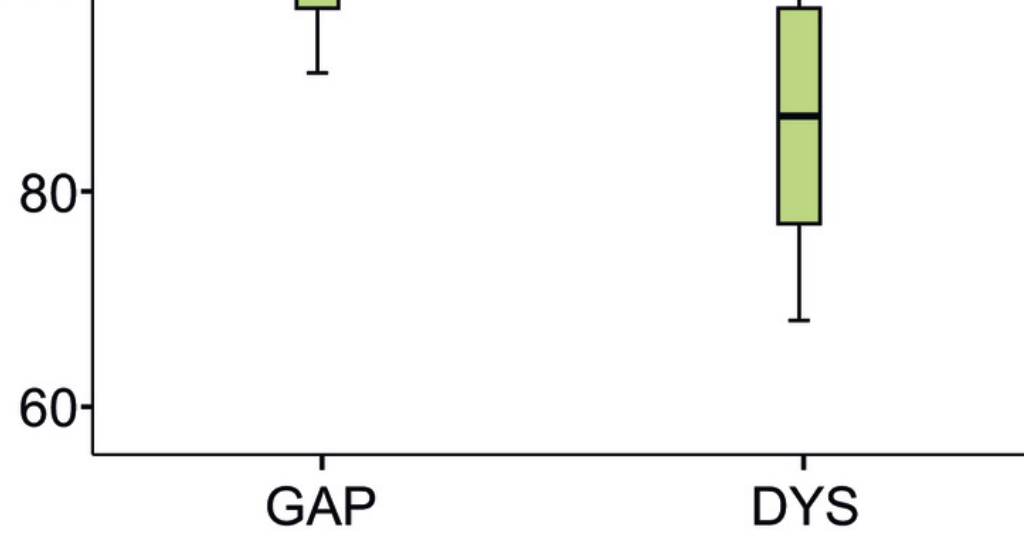

Group 
Figure 2

Depiction of a trial of the addition verification task.

Flowchart of stimuli presentation during individual trials, W: warning stimulus.

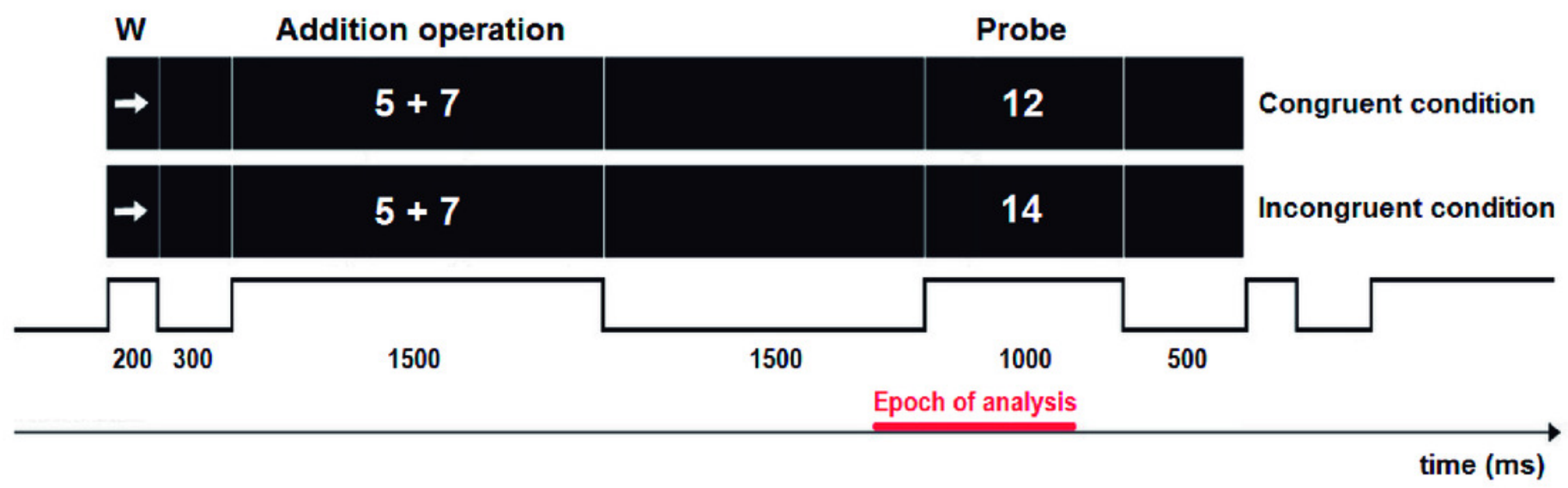




\section{Figure 3}

Workflow of the statistical analyses of ERP data using non-parametric permutation tests.

(A) Definition of analysed time windows, where significant differences between incongruent and congruent conditions (effects) were evinced; comparison between conditions using multiple t-tests, shown at each point of time throughout the electrode sites (colour lines in the coordinate axis). Magenta horizontal lines represent the threshold of $t$-values for $p=$ 0.05 , and grey shadowed boxes represent the analysed time windows where significant differences were found. Colour lines in the coordinate axis represent t-values at different electrode sites. (B) Exploration of the topography of ERP effects (incongruent minus congruent) obtained from (A); t- tests were computed using the mean amplitude values in each condition for each analysed time window (N400 and LPC in the group GAP and LPC in the group DYS) across all electrode sites. (C) Comparison of the ERP-difference wave between the DYS and GAP groups. Mean amplitude values of the difference waves were used to compute the t-tests. (D) Correlation analyses between the working memory index and ERP difference waves for the DYS group, for each electrode site and each ERP window. 
A. Defining analysis time-window

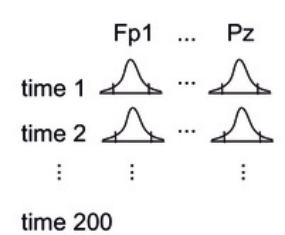

empirical t-test distributions
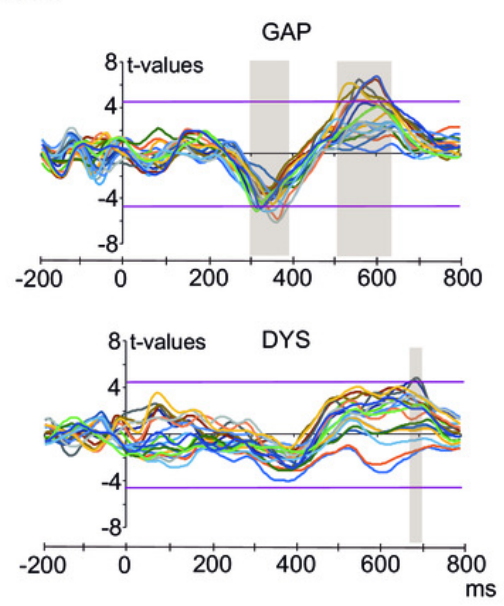

B. Topographical exploration of ERP effects

Comparison incongruent vs congruent

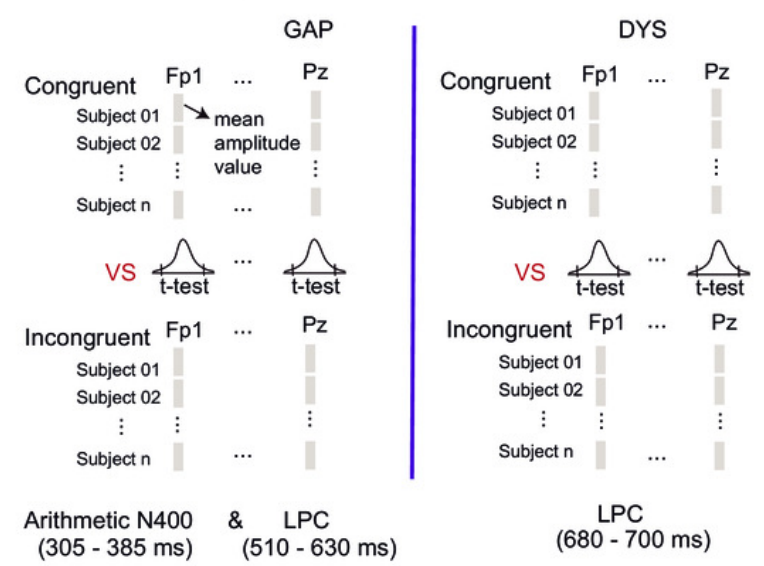

\section{Between-group comparison of ERP effects}

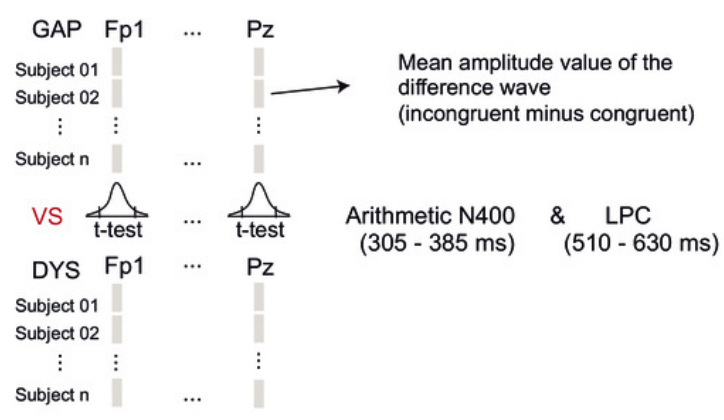

\section{Correlation analyses}
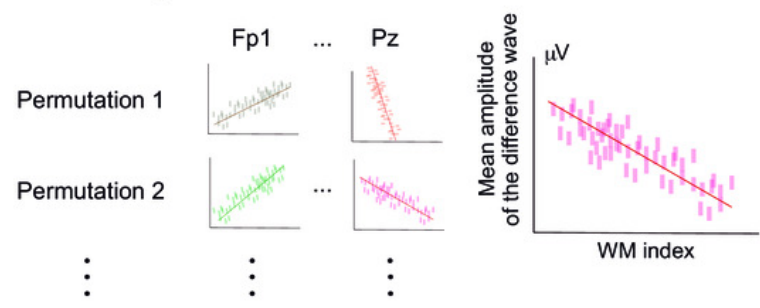

Permutation 5,000

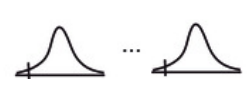

LPC1
$(510-630 \mathrm{~ms})$$\stackrel{\text { LPC2 }}{(680-700 \mathrm{~ms})}$ 
Figure 4

Behavioural data in both groups of children (GAP and DYS) in the arithmetic verification task.

The correct answer (A) and mean response time (B) in both conditions (congruent and incongruent) and both groups of children. Error bars represent the standard deviation. The DYS group showed a lower percentage of correct answers than the GAP group. ${ }^{* * *} p<0.0001$
A.
B.
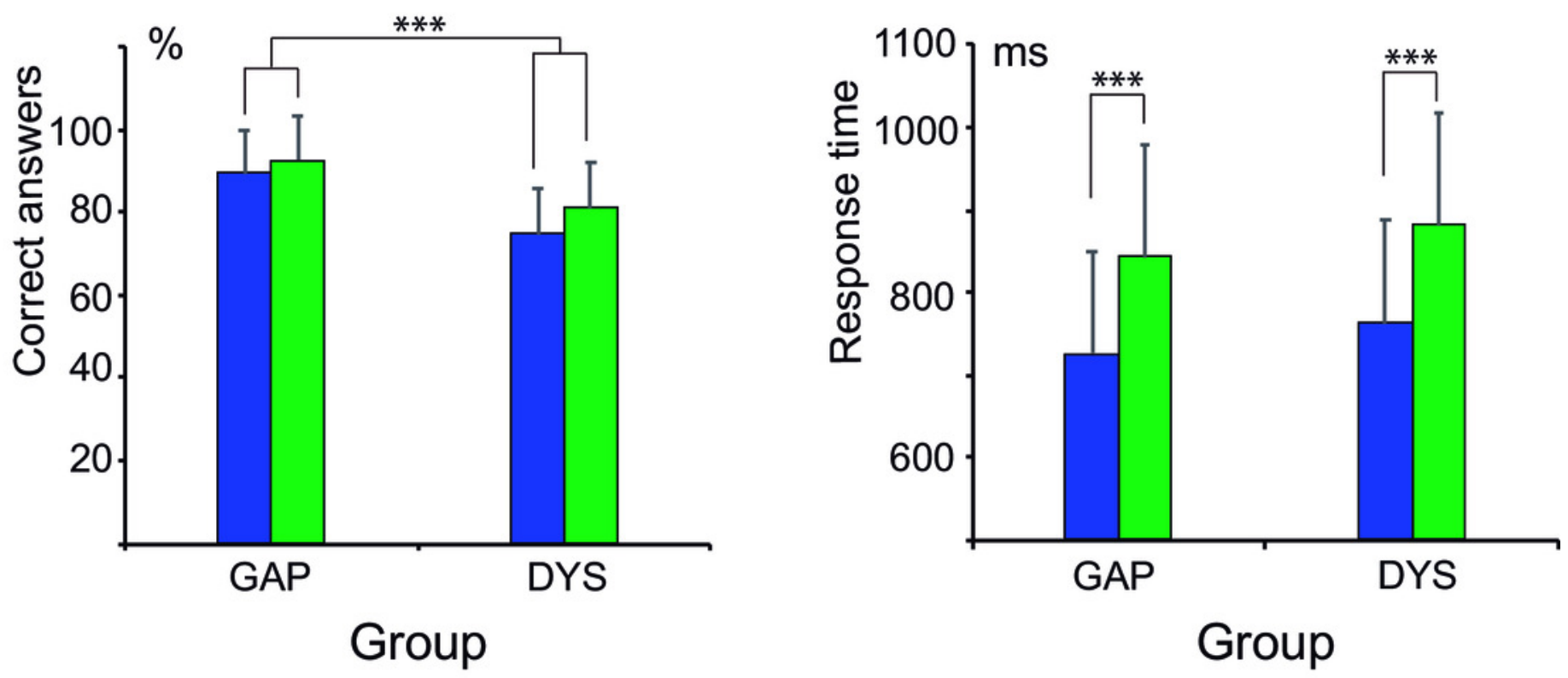

$\square$ Congruent $\square$ Incongruent 


\section{Figure 5}

Statistical parametric maps of the arithmetic N400 and LPC effects in both groups.

Top: GAP group. (A) Differences between conditions at 305 to $385 \mathrm{~ms}$ (arithmetic N400). (B)

Differences between conditions at 510 to $630 \mathrm{~ms}$ (LPC effect). Bottom: DYS group. (C)

Differences between conditions at 680 to $700 \mathrm{~ms}$ (LPC effect). Blue and red colours represent the $t$-values that were above the threshold of significance $(p<0.001)$. In the GAP group, the arithmetic N400 effect was elicited at P3, 01, T4, T5, Fz, and Pz, and the LPC effect was elicited at $\mathrm{C} 4, \mathrm{P} 4, \mathrm{O} 1, \mathrm{O2}, \mathrm{T} 4, \mathrm{~T} 6, \mathrm{Cz}$, and Pz, while in the DYS group, the LPC effect was observed at $\mathrm{P3}$ and 01 . All $p<0.001$ 
A.

B.

GAP group

t-values
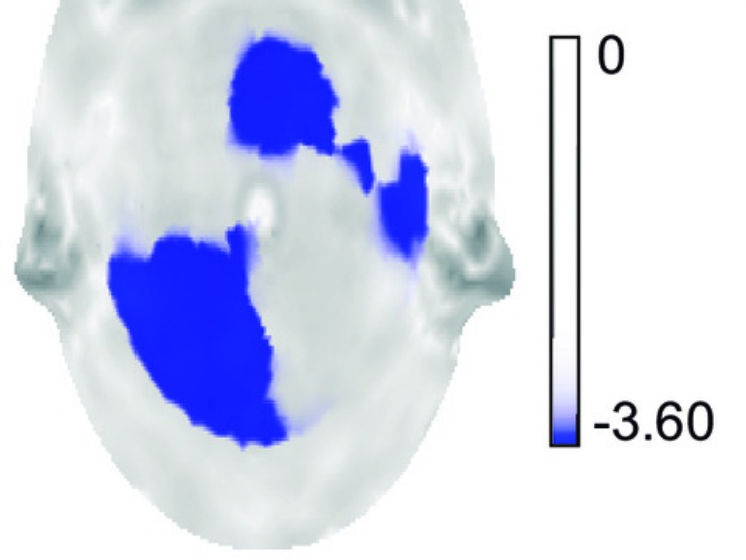

Arithmetic N400

(305 - $385 \mathrm{~ms})$

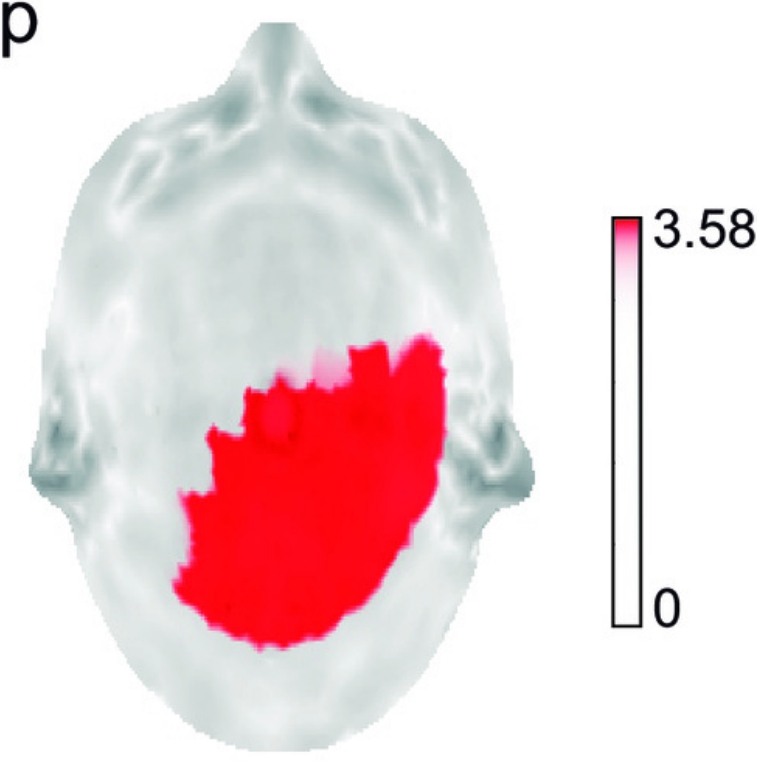

LPC
$(510-630 \mathrm{~ms})$

C.

DYS group

$\mathrm{t}$-values

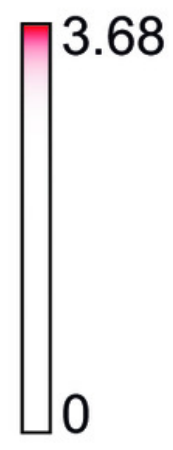


Figure 6

ERP wave grand averages.

(A) T3 electrode. (B) C3 electrode. The GAP group responses to congruent and incongruent conditions are represented by the black continuous and discontinuous lines, while the DYS group responses to congruent and incongruent conditions are represented by the red continuous and discontinuous lines, respectively. Negativity is plotted downwards.

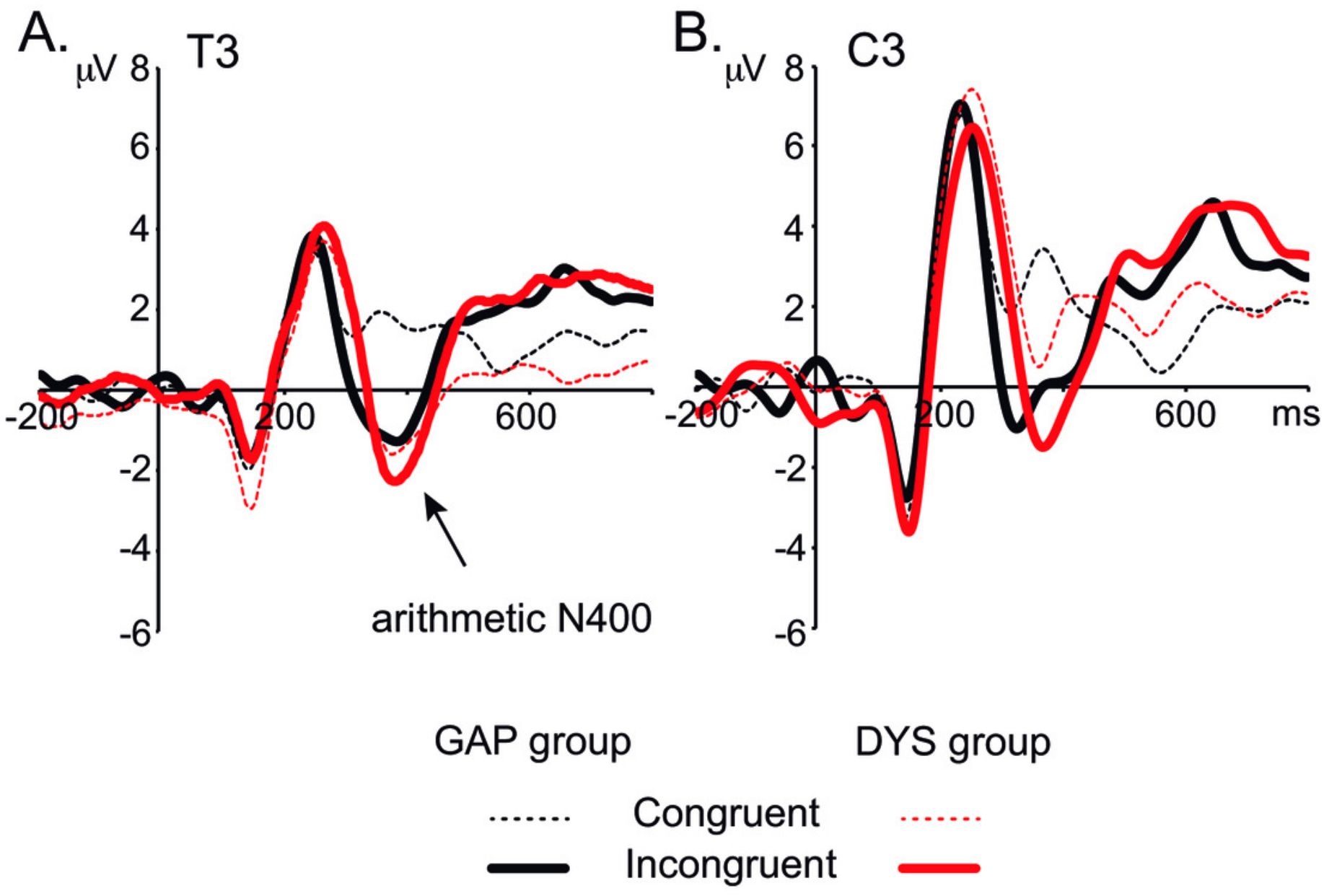


Figure 7

Differences between groups in arithmetic N400 and LPC effects.

(A) Statistical map of the comparison between groups based on the difference between conditions (incongruent minus congruent) for the arithmetic N400 (305-385 ms) at T5. (B)

Statistical map of the comparison between groups based on the difference between conditions (incongruent minus congruent) for the LPC (510-630 ms) at Fp2. The blue and red spots represent significant differences between groups (t-values $p<0.05$ ).

A.

GAP > DYS

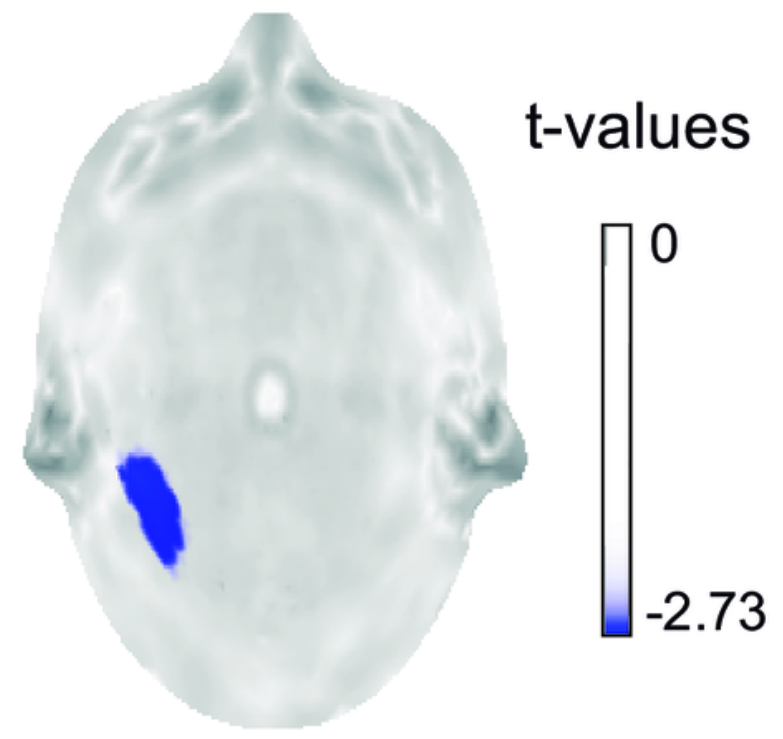

Arithmetic N400 effect

(305 - $385 \mathrm{~ms})$
B.

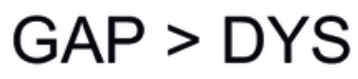

t-values

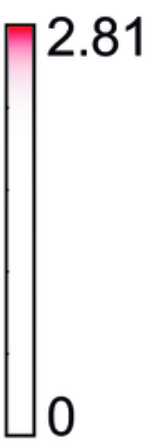

LPC effect

(510 - $630 \mathrm{~ms}$ ) 
Figure 8

Variability of arithmetic N400 and LPC effects.

(A) Box-and-whisker plots of both groups of children (GAP and DYS) using the amplitude values of the arithmetic N400 (305-385 ms) effect. (B) Box-and-whisker plots of both groups of children using the amplitude values of the LPC (510-630 ms) effect. 
A.

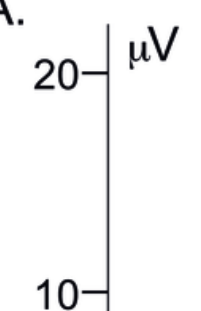

Arithmetic N400

(305 - 385 ms)<smiles>[13CH3]</smiles>

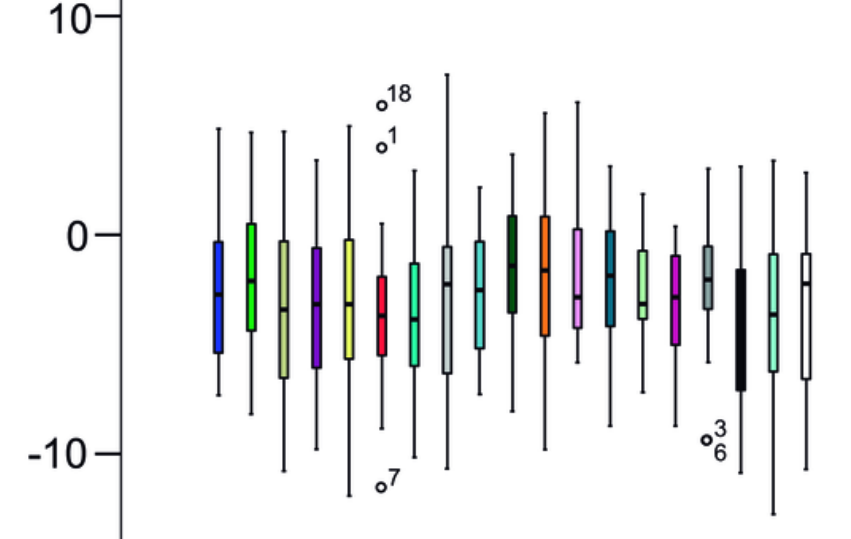

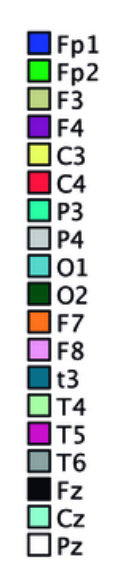

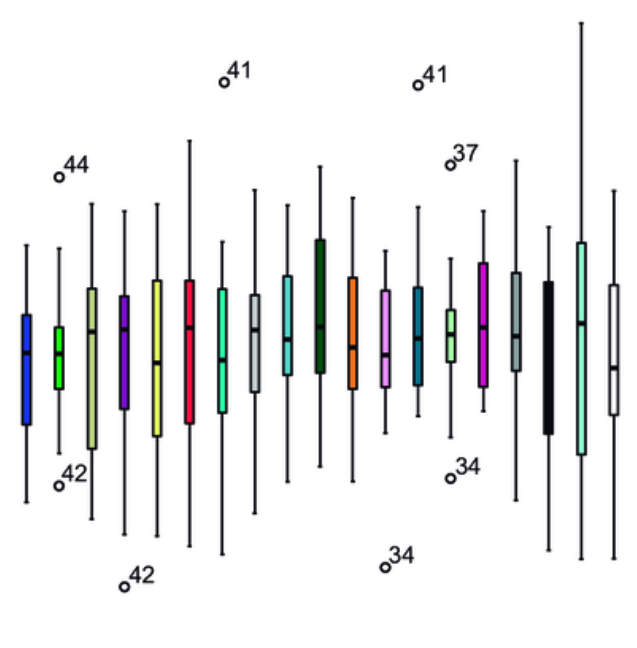

$-20-$

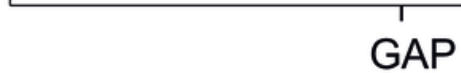

B.

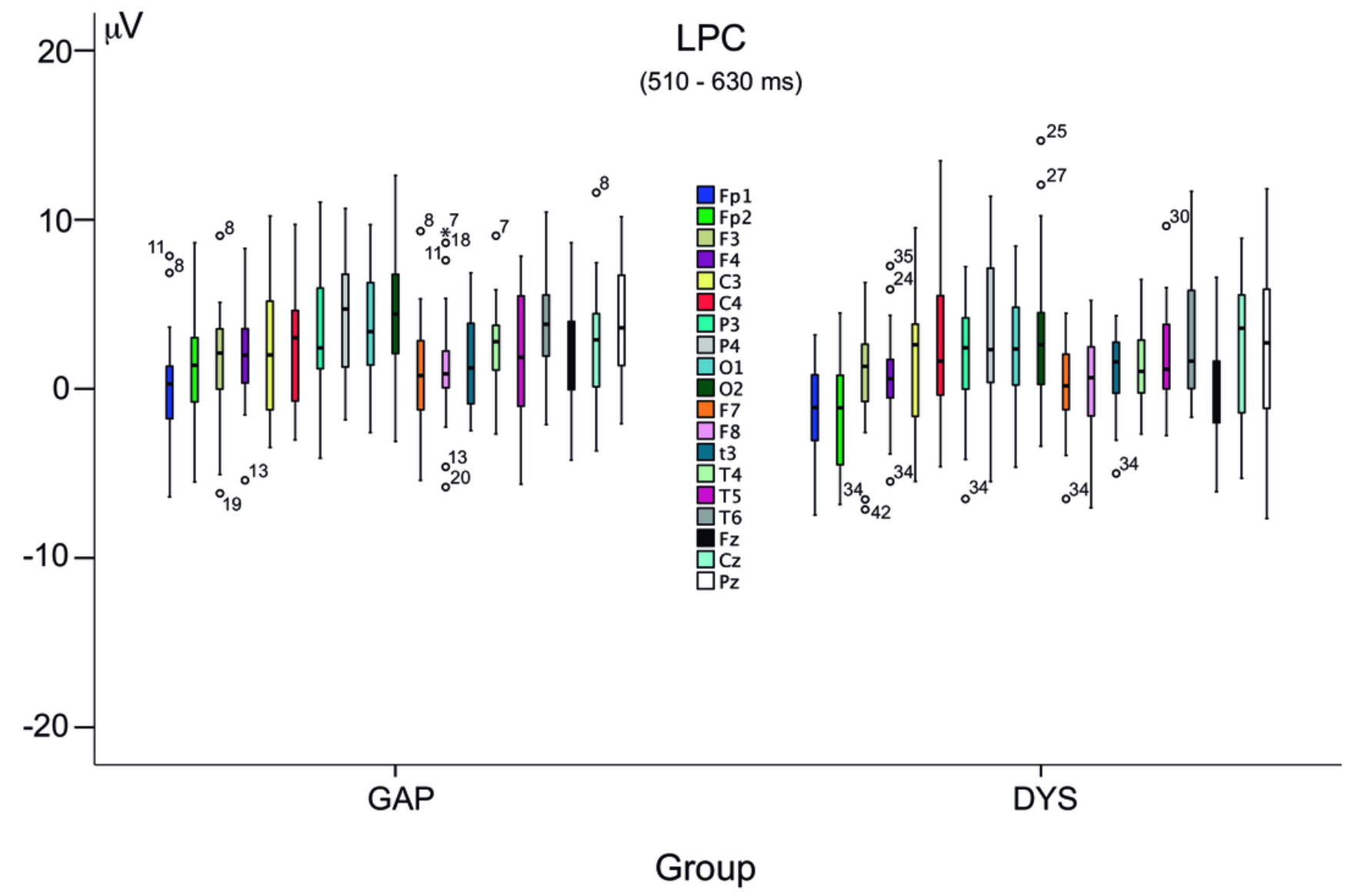




\section{Figure 9}

Grand averages of the difference waves (i.e., incongruent minus congruent condition).

Blue solid lines represent the ERPs for the GAP group. Red solid lines represent the ERPs for the DYS group with high WM index scores and red dotted lines represent those for the DYS group with low WM index scores. Positive is plotted up. The arithmetic N400 effect and the LPC effect in the GAP group are marked with grey-shadow boxes. Black arrows indicate double-negative peaks (195 ms and $405 \mathrm{~ms}$ ) and double-positive peaks (525 ms and $685 \mathrm{~ms}$ ) in the DYS group with low WM scores at P3 and C3, but such effects can be observed over other electrode sites. Each letter represents an electrode. (A) Fp1. (B) Fp2. (C) F3. (D) F4. (E) C3. (F) C4. (G) P3. (H) P4. (I) 01. (J) O2. (K) F7. (L) F8. (M) T3. (N) T4. (O) T5. (P) T6. (Q) Fz. (R) Cz. (S) Pz. 


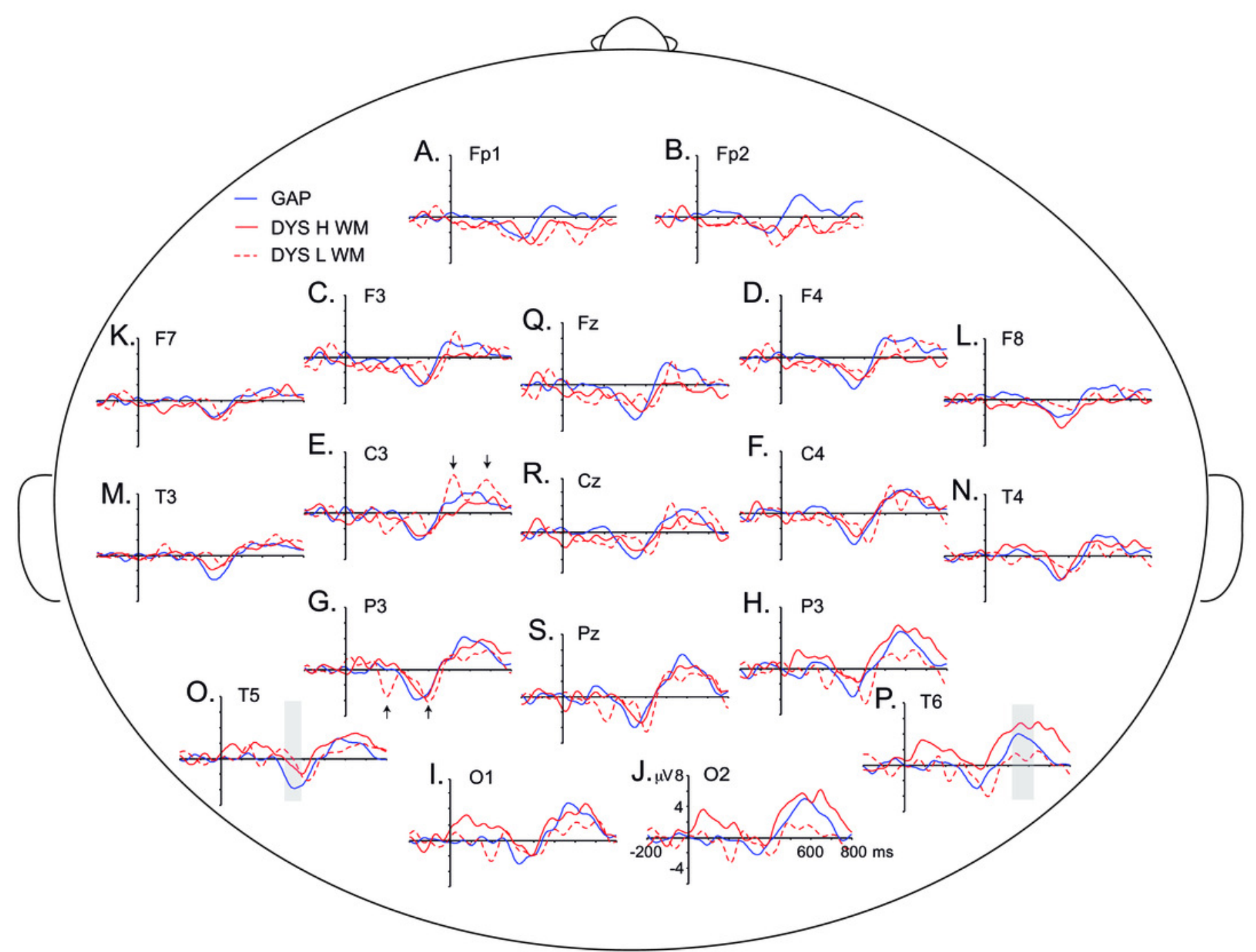




\section{Figure 10}

Relationship between working memory and LPC effect in the DYS group.

(A) Statistical map of the correlations between the WM index and the ERP amplitude difference between conditions (incongruent minus congruent) at 510 to $630 \mathrm{~ms}$ (LPC effect) across electrode sites. The red spot represents the significant $r$ values $(p<0.05)$ over the T6 and 02 electrodes. (B) Ascending regression line showing that higher values of the working memory index ( $\mathrm{X}$ axis) are associated with greater LPC effects in the electrode T6 ( $Y$ axis). (C) Ascending regression line showing that higher values of the working memory index ( $X$ axis) are associated with greater LPC effect in the electrode $\mathrm{O2}$ ( $\mathrm{Y}$ axis). 
A.

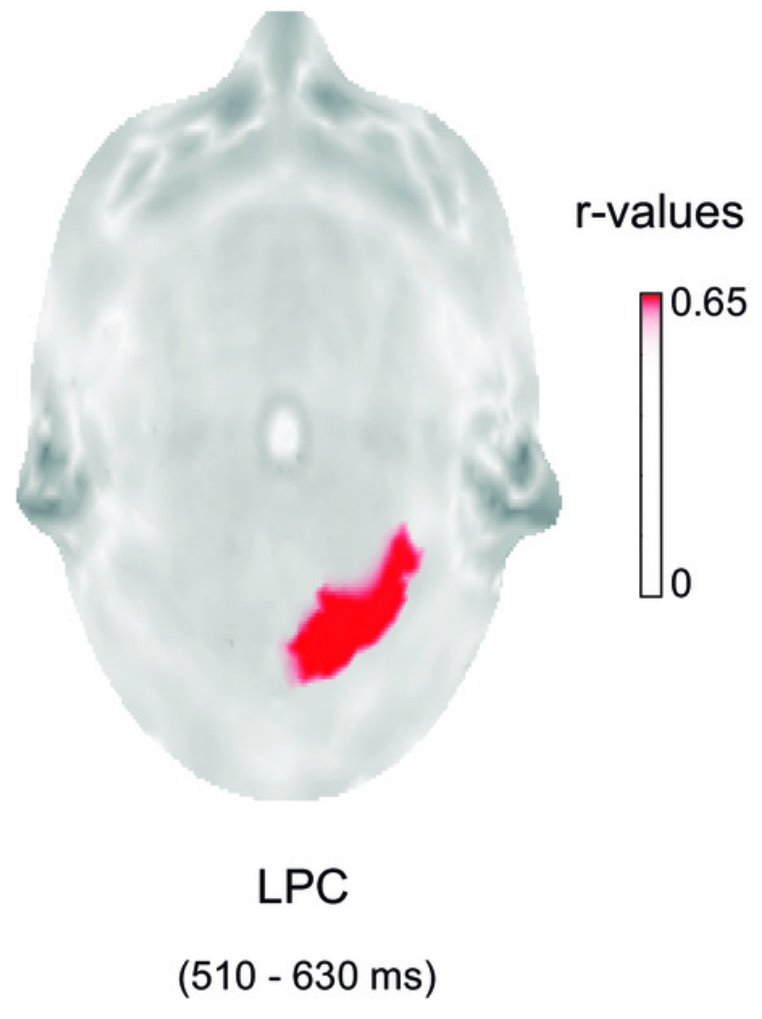

D.

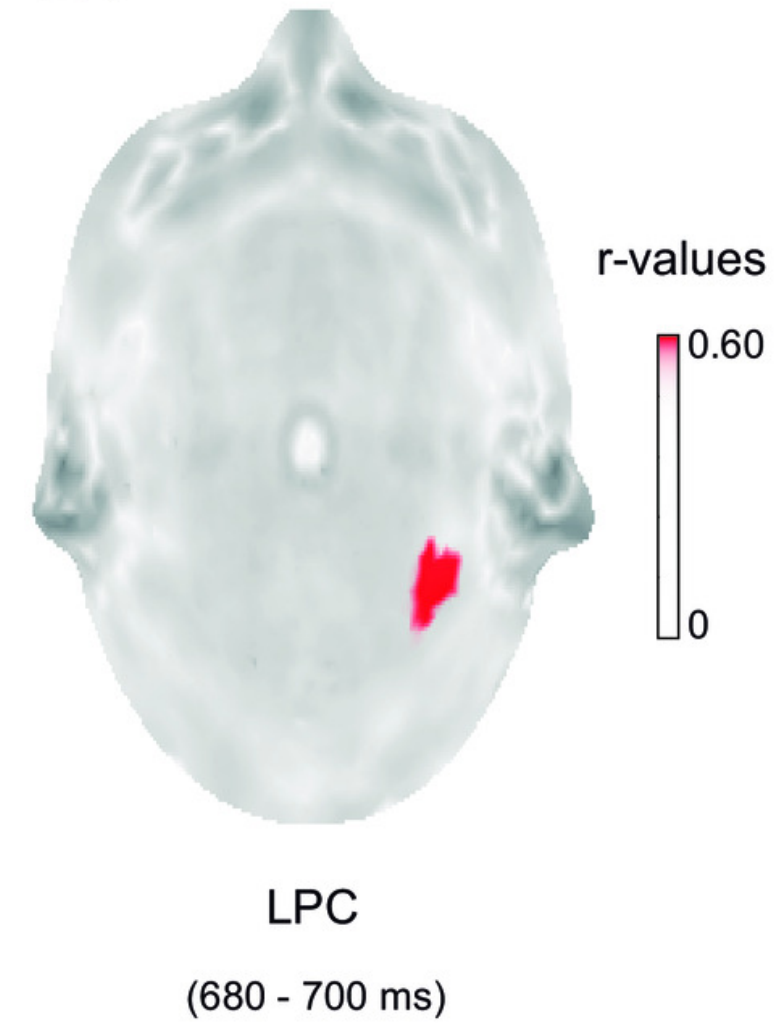

B.

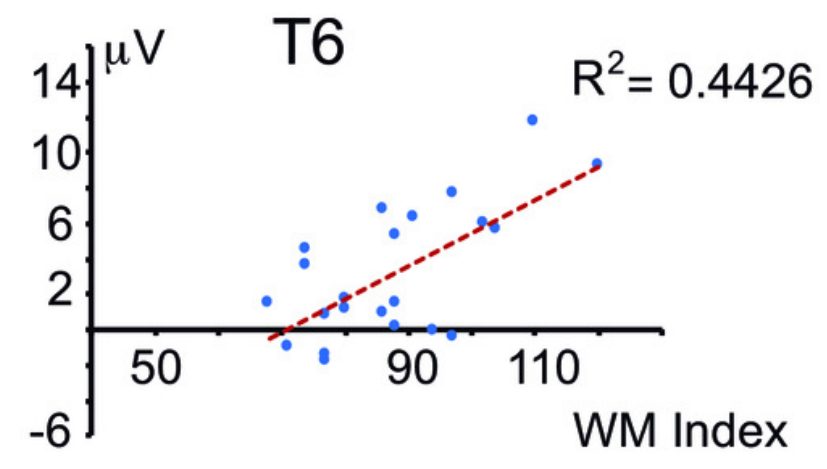

C.

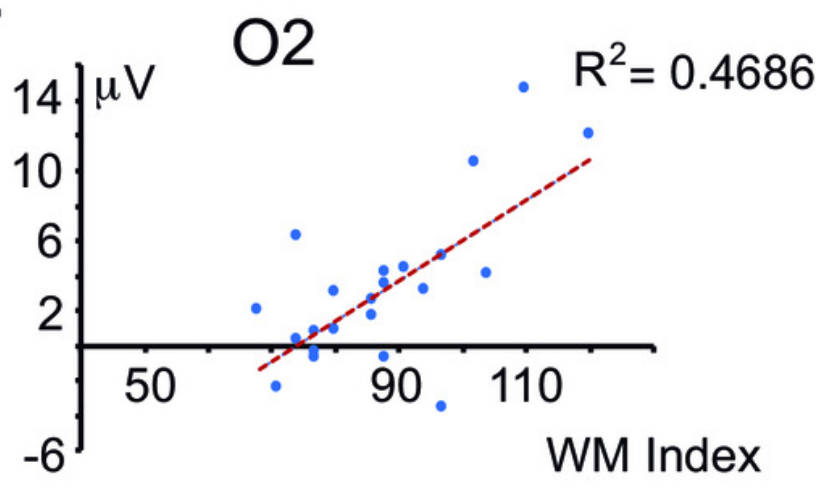

E.

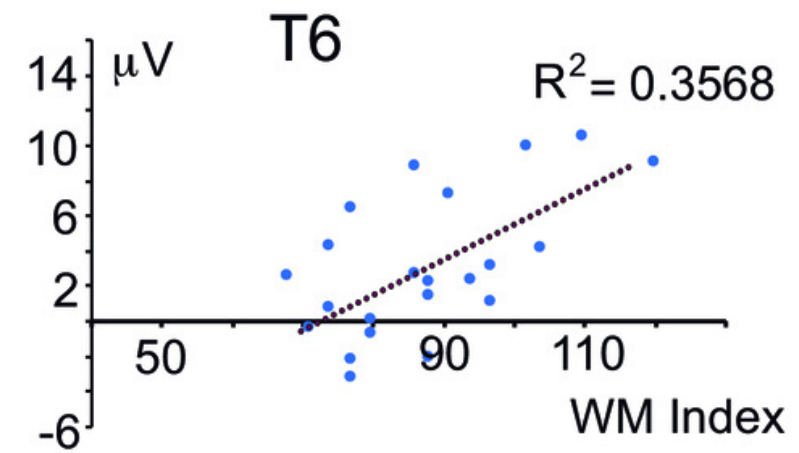

